\title{
Article
}

\section{Wound Healing Composite Materials of Bacterial Cellulose and Zinc Oxide Nanoparticles with Immobilized Betulin Diphosphate}

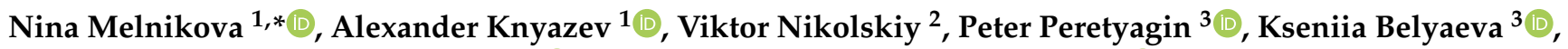 \\ Natalia Nazarova ${ }^{4}$, Elena Liyaskina ${ }^{4} \mathbb{D}$, Darina Malygina ${ }^{5}$ and Viktor Revin ${ }^{4} \mathbb{C}$ \\ 1 Faculty of Chemistry, Lobachevsky University, 23/5 Gagarin Av., 603950 Nizhny Novgorod, Russia; \\ knyazevav@gmail.com \\ 2 Nizhni Novgorod Regional Clinical Hospital named after N.A. Semashko, 190 Rodionova str., \\ 603126 Nizhny Novgorod, Russia; viktor22031@yandex.ru \\ 3 Department of Experimental Medicine, Privolzhsky Research Medical University, 10/1 Minin sq., \\ 603950 Nizhny Novgorod, Russia; peretyaginpv@gmail.com (P.P.); skoln94@mail.ru (K.B.) \\ 4 Department of Biotechnology, Bioengineering and Biochemistry, National Research Ogarev Mordovia State \\ University, 68 Bolshevistskaya str., 430005 Saransk, Russia; fac-bio@adm.mrsu.ru (N.N.); \\ liyaskina@yandex.ru (E.L.); revinvv2010@yandex.ru (V.R.) \\ 5 Department of Pharmaceutical Chemistry, Privolzhsky Research Medical University, 10/1 Minin sq., \\ 603950 Nizhny Novgorod, Russia; mds73@yandex.ru \\ * Correspondence: melnikovanb@gmail.com; Tel.: +79-023092298
}

Citation: Melnikova, N.; Knyazev, A.; Nikolskiy, V.; Peretyagin, P.; Belyaeva, K.; Nazarova, N.; Liyaskina, E.; Malygina, D.; Revin, V. Wound Healing Composite Materials of Bacterial Cellulose and Zinc Oxide Nanoparticles with Immobilized Betulin Diphosphate. Nanomaterials 2021, 11, 713. https://doi.org/ 10.3390/nano11030713

Academic Editor: Maria

Letizia Manca

Received: 9 February 2021

Accepted: 9 March 2021

Published: 12 March 2021

Publisher's Note: MDPI stays neutral with regard to jurisdictional claims in published maps and institutional affiliations.

Copyright: (c) 2021 by the authors. Licensee MDPI, Basel, Switzerland. This article is an open access article distributed under the terms and conditions of the Creative Commons Attribution (CC BY) license (https:// creativecommons.org/licenses/by/ $4.0 /)$.
Abstract: A design of new nanocomposites of bacterial cellulose (BC) and betulin diphosphate (BDP) pre-impregnated into the surface of zinc oxide nanoparticles (ZnO NPs) for the production of wound dressings is proposed. The sizes of crystalline BC and ZnO NPs (5-25\%) corresponded to 5-6 nm and 10-18 nm, respectively (powder X-ray diffractometry (PXRD), Fourier-infrared (FTIR), ultraviolet (UV), atomic absorption (AAS) and photoluminescence (PL) spectroscopies). The biological activity of the wound dressings "BC-ZnO NPs-BDP" was investigated in rats using a burn wound model. Morpho-histological studies have shown that more intensive healing was observed during treatment with hydrophilic nanocomposites than the oleophilic standard (ZnO NPs-BDP oleogel; $p<0.001$ ). Treatment by both hydrophilic and lipophilic agents led to increases in antioxidant enzyme activity (superoxide dismutase (SOD), catalase) in erythrocytes and decreases in the malondialdehyde (MDA) concentration by 7,10 and 21 days $(p<0.001)$. The microcirculation index was restored on the 3rd day after burn under treatment with BC-ZnO NPs-BDP wound dressings. The results of effective wound healing with BC-ZnO NPs-BDP nanocomposites can be explained by the synergistic effect of all nanocomposite components, which regulate oxygenation and microcirculation, reducing hypoxia and oxidative stress in a burn wound.

Keywords: bacterial cellulose; wound dressings; zinc oxide nanoparticles; betulin diphosphate; antioxidant properties; burns

\section{Introduction}

Recently, biodegradable materials, biocompatible to body tissues, based on bacterial cellulose (BC) for the treatment of skin diseases, burns and wounds of various etiologies, have attracted great interest [1]. The need for these materials is due to their bactericidal effect, their ability to absorb large amounts of exudate and remove unwanted products from the wound, and their possibility of immobilizing active pharmaceutical ingredients (antibiotics, steroid hormones, etc.) into the bacterial cellulose matrix. In the treatment of burns, biologically active substances that promote collagen production, such as pentacyclic triterpenoids, including betulinic acid derivatives [2], are of great importance. In rats and mice experiments, we have previously shown that betulin diphosphate (BDP) exhibits antitumor, antioxidant, and anti-burn properties [3,4]. 
The components for the formation of $\mathrm{BC}$ nanomaterials can improve its properties and act as a vector for delivering drugs with low bioavailability. It is a convenient method for obtaining new wound dressings and drugs.

The most acceptable form of new wound dressings is BC nanomaterials with nanoscale inorganic particles, such as gold, silver, and metal oxides (copper oxide, titanium oxide, zinc oxide, etc.). Among the BC nanomaterials with metal nanoparticles, composites with zinc oxide nanoparticles ( $\mathrm{ZnO}$ NPs), which are of particular importance in treating skin diseases should be noted [5-15]. Several factors determine the effect of zinc oxide on wound healing: (i) zinc ions are biogenic; (ii) zinc ions are part of many enzymes and indirectly control the activity of more than 200 enzymes; (iii) they exhibit immunomodulatory properties [16]; and (iv) a small part of zinc ions produced by ZnO NPs have high wound skin permeability $[17,18]$.

Zinc oxide nanoparticles can affect indirect antioxidant properties and be potential regulators of redox imbalance during the burn disease due to tissue hypoxia in the wound. ZnO NPs' influence on oxidative stress, increases the generation of reactive oxygen species (ROS) but increases antioxidant enzyme defense and regulates energy metabolism [18-22].

The destruction of tissue and damage to the epithelium leads to a disruption in the microcirculation system, increasing hypoxia and suppressing tissue respiration, which slows down the repair process $[23,24]$. Zinc oxide nanoparticles promote the regeneration of damaged tissues by activating collagen synthesis $[16,25,26]$.

A serious obstacle to the widespread medical use of ZnO NPs is the possibility of forming rigid protein crowns (or protein composites) on the surface of nanoparticles in a biological environment. The formation of protein corona (PC) most rapidly occurs on the surface of hydrophilic unprotected particles in a liquid medium [27-31]. The presence or absence of the PC usually affects the cytotoxicity of the material. Traditional protection of $\mathrm{ZnO}$ NPs is functionalization with protein repellent molecules such as (Polyethylene glycol) PEG or phosphoric polyesters [32,33], which reduce protein adsorption and decrease binding to surface proteins.

In previous work [34], we studied adsorption on the surface of ZnO NPs, Langmuir monolayers of BDP on an aqueous subphase containing zinc ions. We transferred BDP monolayers onto quartz and $\mathrm{CaF}_{2}$ using the FTIR method. We proved that zinc ions are strongly bound on the surface of ZnO NPs with polar BDP phosphate groups, providing hydrophobicity of modified ZnO NPs. We can assume that the protection of ZnO NPs by BDP and pretreatment of BC with BDP can reduce the protein crown's formation.

BDP, which has anti-burn properties and has two active phosphate groups in its molecule, performs several functions in a nanocomposite. BDP can interact with zinc ions of $\mathrm{ZnO}$ NPs, protect the nanoparticles from aggregation, and be sorbed into BC.

In this work, we developed new nanocomposites of $\mathrm{BC}$ with $\mathrm{ZnO}$ NPs and betulin diphosphate pre-impregnated into the surface of ZnO NPs or BC for wound dressings and the study of their biological activity on a thermal burn model in rats.

The objectives of the study were: (i) estimation of the physicochemical properties of "protected ZnO NPs", "BDP-impregnated ZnO NPs", and BC-ZnO NPs-BDP nanocomposites; (ii) zinc ions release and cell viability analysis; (iii) investigation of wound healing properties of the obtained BC-ZnO NPs-BDP nanocomposites in an experiment in rats on a model of deep second-degree burn wound according to morphological and histological studies and microcirculation data; and (iv) estimation of biochemical indexes (the activity of enzymatic antioxidant defense (superoxide dismutase (SOD), catalase), malondialdehyde (MDA) level) during the treatment with the BC-ZnO NPs-BDP nanocomposite.

\section{Materials and Methods}

\subsection{Preparation of $B C$}

$\mathrm{BC}$ was produced in a static culture medium by Komagataeibacter sucrofermentans $\mathrm{H}-110$, which was isolated from Kombucha tea and identified by sequencing the amplified product of $16 \mathrm{~S}$ rRNA [35]. A strain was deposited in the Russian National Collection of 
Industrial Microorganisms (VKPM) (Accession No. VKPM: B-11267). For the production of $B C$, a Hestrin and Schramm (HS) medium that contained glucose $\left(20 \mathrm{~g} \cdot \mathrm{L}^{-1}\right)$, peptone $\left(5 \mathrm{~g} \cdot \mathrm{L}^{-1}\right)$, yeast extract $\left(5 \mathrm{~g} \cdot \mathrm{L}^{-1}\right)$, citric acid $\left(1.15 \mathrm{~g} \cdot \mathrm{L}^{-1}\right)$, and disodium hydrogen phosphate $\left(2.7 \mathrm{~g} \cdot \mathrm{L}^{-1}\right)$ at a $\mathrm{pH}$ of 6.0 was used. The culture medium was autoclaved for $20 \mathrm{~min}$ at $120{ }^{\circ} \mathrm{C}$. Further, the medium was inoculated with $10 \%(v / v)$ inoculum. To prepare the inoculum, K. sucrofermentans $\mathrm{H}-110$ was transferred aseptically from an agar plate to a $250 \mathrm{~mL}$ Erlenmeyer flask containing $100 \mathrm{~mL}$ of culture medium and placed into a shaker incubator (model ES-20/60, BIOSAN, Latvia) at $28^{\circ} \mathrm{C}$ for $24 \mathrm{~h}$ at $250 \mathrm{rpm}$. The BC was produced in static conditions at $28^{\circ} \mathrm{C}$ for $5 \mathrm{~d}$. After the incubation, the $\mathrm{BC}$ was collected, washed thoroughly with de-ionized water to remove medium components, and treated with $1 \%(w / v)$ sodium hydroxide solution at $80^{\circ} \mathrm{C}$ for $1 \mathrm{~h}$ to eliminate the bacterial cells. Further, the $\mathrm{BC}$ was rinsed extensively with $6 \%(v / v)$ acetic acid and then de-ionized water until the $\mathrm{pH}$ became neutral. If necessary, the purified $\mathrm{BC}$ was dried to a constant weight at $60{ }^{\circ} \mathrm{C}$. The ${ }^{13} \mathrm{C}$ nuclear magnetic resonance (NMR) spectrum of BC used in this study is typical spectrum of BC crystal structure [36-39] (Figure S1). There are four spectral regions in the BC spectrum: (i) C-1 acetal signal (105.57 ppm); (ii) C-4 signals (double peak corresponds to the crystalline (89.4 ppm, approximately $85 \%$ ) and amorphous (84.47 ppm, approximately $15 \%$ ) forms of $\mathrm{BC}$ ); (iii) C-2, C-3, and C-5 signals in the pyranose ring in the region of 71.47-75.04 ppm; and (iv) C-6 (65.76 ppm).

\subsection{Betulin-3,28-diphosphate}

Betulin-3,28-diphosphate (BDP, 3 $\beta$,28-diphosphate-lup-20(29)-ene) was synthesized according to the procedure [40].

\subsection{Zinc Oxide Nanoparticles}

Two methods of ZnO NPs preparation were used in this work.

(1) Sol-gel methods using fresh prepared ethanol solutions: $2 \% \mathrm{NaOH}(10 \mathrm{~mL}), 1.5 \%$ zinc acetate dihydrate $(30 \mathrm{~mL})$ at $70{ }^{\circ} \mathrm{C}$. NaOH solution was added by drops to zinc acetate dihydrate solution at cooling and mixing in an ice bath for 5-10 min. The precipitation of $\mathrm{ZnO} N$ Ps from the transparent sol was carried out by addition of n-heptane followed by vigorous stirring. The ratio of volume of n-heptane to sol was 3:2. After centrifugation, the precipitate was collected and redispersed into ethanol. The removal of excess acetate and sodium ions from the dispersed $\mathrm{ZnO}$ was accomplished by repetitive washing of $\mathrm{ZnO}$ with ethanol and n-heptane [41].

We protected the obtained $\mathrm{ZnO}$ NPs before forming the composite by additional treatment with a $0.5 \mathrm{M}$ alcohol solution of $\mathrm{BDP}$ at $\mathrm{pH} 3.75-4.10$. In the text, the designation of these nanoparticles is $\mathrm{ZnO}$ NPs.

(2) We used freshly prepared ethanol solutions of the $0.025 \mathrm{M}$ zinc acetate dihydrate and a $0.175 \mathrm{M}$ lithium hydroxide solution, which was sonicated for $30 \mathrm{~min}$. Then $1 \mathrm{~g}$ of PEG 400 was added to the solution; the solution was re-sonicated for $40 \mathrm{~min}$; after that, we added the alkali solution. The resulting solution was sonicated for $5 \mathrm{~min}$ at $\mathrm{t}=30^{\circ} \mathrm{C}$. To precipitate the white zinc oxide particles formed in the volume, $5 \mathrm{~g}$ of cetyl alcohol was used and stirred for 5-7 min. After separation of the liquid and solid phases, the white precipitate was repeatedly washed with $96 \%$ ethanol to remove unreacted substances. The precipitate was dried at room temperature for $3 \mathrm{~h}$, then placed in a desiccator [42].

We protected the obtained $\mathrm{ZnO}$ NPs before forming the composite by additional treatment with a $0.5 \mathrm{M}$ alcohol solution of $\mathrm{BDP}$ at $\mathrm{pH} 3.75-4.10$. In the text, the designation of these nanoparticles is $\mathrm{ZnO}$ NPs-PEG.

UV and PL spectra are shown in Figure S2.

\subsection{Oleogel $\mathrm{ZnO} N P_{s-B D P}$}

Oleogel $\mathrm{ZnO}$ NPs-BDP preparation and properties were described in detail in paper [3]. Formulation of oleogel, \%: ZnO NPs (5.0), BDP (1.0), and sunflower oil up to 100.0. 


\subsection{Preparation of $B C-Z n O N P s-B D P$ Composites and Their Properties}

The BC film was placed in aqueous alcohol solutions containing trisamine $(1 \%)$, or DDS-Na $(0.01 \%)$ or benzalkonium chloride $(0.1 \%)$, and BDP $(1 \%)$ for swelling for $30 \mathrm{~min}$. After removing the film, a suspension of an aqueous-alcoholic solution of zinc oxide nanoparticles was sprayed onto the surface of an elastic polymer mesh at the rate of $5 \% \mathrm{ZnO}$ NPs per $100 \%$ of the initial BC film. After removing the excess solvent by vacuum drying, the films were closed on both sides with parchment and sealed in cellophane envelopes.

When treating rats with BC-ZnO NPs, BC-BDP, and BC-ZnO NPs-BDP composite coatings, the composite coatings were additionally moistened with $0.9 \%$ sodium chloride solution in the presence of $0.01 \%$ lidocaine and $0.01 \%$ benzalkonium chloride.

X-ray phase analysis was performed on additionally dried samples, which were stored in a desiccator.

An alternative method for the preparation of $\mathrm{BC}-\mathrm{ZnO}$ NPs composites included the primary treatment of the film with an aqueous solution of $\mathrm{Zn}\left(\mathrm{NO}_{3}\right)_{2} \cdot 4 \mathrm{H}_{2} \mathrm{O}$. The $\mathrm{BC}$ film was removed and transferred into a shallow container with $0.1 \mathrm{M}$ solution of $\mathrm{NaOH}$ for $10 \mathrm{~min}$ at $50{ }^{\circ} \mathrm{C}$. Then the film was rinsed with distilled water until the composite $\mathrm{pH}$ became neutral, and after that it was dried.

\subsection{FTIR Analysis}

FTIR spectra in $400-4000 \mathrm{~cm}^{-1}$ range were measured by an IR Prestige-21 FTIR spectrometer (Shimadzu, Kyoto, Japan) equipped with a KBr beam splitter. A pellet from a well-dried $\mathrm{KBr}$ was prepared according to standard cold pressing. The resolution was $0.5 \mathrm{~cm}^{-1}$ and the number of scans was 45 .

\subsection{UV Analysis}

UV spectra were recorded by UV-1800 (Shimadzu, Kyoto, Japan).

\subsection{RP-HPLC Analysis}

Reversed phase high-performance liquid chromatography analysis was carried out on an LC-20Avp (Shimadzu, Kyoto, Japan) with UV-detection, the column is Discovery C18 $(25 \mathrm{~cm} \times 4.6 \mathrm{~mm}, 5 \mu \mathrm{m}$, Supelco).

\subsection{Powder X-ray Diffraction Analysis}

Powder X-ray diffraction patterns were obtained using Shimadzu X-ray diffractometer XRD-6000 (Shimadzu, Kyoto, Japan) at 295(2) K with Cu K $\alpha$ radiation $(\lambda=1.5418 \AA$ ), in the Bragg-Brentano reflection geometry. The samples were collected in the $2 \theta$ range between 5 and $50^{\circ}$ with steps of $0.026^{\circ}$ and $100 \mathrm{~s}$ step size, using a scan speed $(\% / \mathrm{s})$ of 0.067335 . On the $\mathrm{X}$-ray diffraction patterns of amorphous samples, there are diffraction peaks at $37.5^{\circ}$ and $44.0^{\circ}$ referring to the cuvette material.

\subsection{Photoluminescence Analysis}

Fluorescent spectra were obtained using spectrofluorimeter RF-600 (Shimadzu, Kyoto, Japan) at the length of $320 \mathrm{~nm}$ in the field $350-800 \mathrm{~nm}$ in a $10 \mathrm{~mm}$ thick cuvette.

\subsection{Elemental Analysis}

Elemental analysis was carried out using atomic absorption spectrophotometer AA7000 (Shimadzu, Kyoto, Japan) at $213.9 \mathrm{~nm}$. The samples were digested with $\mathrm{HNO}: \mathrm{HClO} 4$ (6:1) to leach out zinc metal.

\subsection{2. ${ }^{13} \mathrm{C}$ Nuclear Magnetic Resonance (NMR) Spectroscopy}

The measurements of solid-state ${ }^{13} \mathrm{C}$ NMR spectra were performed on a JEOL JNMECX400 spectrometer (JEOL, Tokyo, Japan) $(9.39 \mathrm{~T}, 100.5 \mathrm{MHz})$ in the solid phase at room temperature using a cross-polarization technique (CPMAS) with a rotation speed of $10 \mathrm{kHz}$ in $7 \mathrm{~mm}$ zirconium dioxide rotors. The angle of rotation of the sample (VUS) was defined 
at a rotation speed of $10 \mathrm{kHz}$. All MAS experiments were carried out at room temperature. Proton decoupling was performed by double-pulse phase modulation (TPPM). The measurements of ${ }^{13} \mathrm{C}$ magic angle spinning (MAS) NMR spectra were performed using the rotor synchronization of the echo sequence (RSE) or the one-setting pulse (SP) at a Larmor frequency of $100.6 \mathrm{MHz}$. To optimize the process of spectrum detection, the relaxation time of carbon nuclei was identified. The impulse duration for an angle of $90^{\circ}$ was 6 ms and for $180^{\circ}$ was $12 \mathrm{~ms}$, with a total of 256 scans. Spectra were processed using ACD/NMR Processor Academic Edition, version 12.01.

\subsection{SEM Analysis}

The morphology of the samples was obtained by scanning electron microscopy (SEM) on JSM-IT300LV (JEOL, Tokyo, Japan) with the electron probe diameter of about $5 \mathrm{~nm}$ and probe current below $0.5 \mathrm{nA}$ (operating voltage $20 \mathrm{kV}$ ). The study of the sample surface topography was performed using the low-energy secondary electrons and backscattered electrons under low vacuum mode to eliminate charging.

\subsection{Specific Surface Areas Analysis}

Specific surface areas (SSAs) of the ZnO NPs were analyzed using an analyzer of specific surface area and adsorption porosity ASAP 2020 (Micromeritics, Norcross, GA, USA).

\subsection{Chemical Composition of $B C$}

Chemical composition of $\mathrm{BC}$ was analyzed by determining $\mathrm{C} / \mathrm{O} / \mathrm{N}$ using a Flash EA 1112 CN analyzer (NEOLAB Ltd., Italy). Analysis for major and trace elements was performed with an atomic absorption spectrophotometer AA-7000 (Shimadzu, Kyoto, Japan) after wet mineralization of cellulose samples with a mixture of perchloric and nitric acids.

\subsection{Surface Charge Measurements}

Surface charge of the nanoparticles was measured using the zeta potential mode of the Zetasizer Nano ZSP (Grovewood Road, Malvern, Worcestershire, UK). Suspensions having a solid loading of $0.02 \mathrm{~g} / \mathrm{L}$ were prepared in the presence $\left(1 \times 10^{-3} \mathrm{M}\right)$ as well as in the absence of BDP water-ethanol (1:1) solution and were allowed to equilibrate for $24 \mathrm{~h}$ to reach the steady-state. Surface charge measurements were obtained for samples of sizes 10-20 nm.

\subsection{Biological Activity}

Male Wistar rats (150-200 g) were involved in the study. The animals were purchased from the Animal Breeding Facilities "Andreevka" Federal State Budgetary Institution of Science "Scientific Center for Biomedical Technologies" of the Federal Medical and Biological Agency (Andreevka, Moscow region, Russia). The animals were handled humanely, kept in plastic suspended cages, and placed in a well-ventilated and hygienic rat house under suitable conditions of room temperature $\left(27 \pm 2{ }^{\circ} \mathrm{C}\right)$ and humidity. They were given food and water ad libitum and subjected to a natural photoperiod cycle of $12 \mathrm{~h}$ light and $12 \mathrm{~h}$ dark. The animals were allowed two weeks of acclimatization before the commencement of all animal model experiments in the study.

All blood taking and withdrawal of animals for the experiment were performed under anesthesia, all efforts being made to minimize suffering.

\subsubsection{Modeling of Thermal Burns in Animals}

The surface of the animal's back was burned using electromagnetic radiation from an infrared soldering station YaXunXY865D following the requirements of Good Laboratory Practice for experimental modeling of thermal burns in laboratory animals. We used the regime that causes deep second-degree thermal burns. The distance of the infrared heater from the animal's skin was $15 \mathrm{~mm}$, the temperature on the skin in the heating zone was 
$60{ }^{\circ} \mathrm{C}$, the heating duration was $23 \mathrm{~s}$, and the power was $100 \mathrm{~W}$. Under these conditions, infrared radiation penetrates to a depth of 3-5 $\mathrm{mm}[43,44]$. Standard thermal burns had an area of $14.0 \pm 0.5 \mathrm{~cm}^{2}$. The body surface area of each animal was evaluated by the weight of the animal using the Mee-Rubner formula [45]. The minimum weight of the rats was $240 \mathrm{~g}$, the maximum was $330 \mathrm{~g}$, and the average weight of the rats was $285.0 \pm 5.0 \mathrm{~g}$. The minimum body surface area of the experimental animals was $436.0 \mathrm{~cm}^{2}$, the maximum was $555.0 \mathrm{~cm}^{2}$, and the average was $494.0 \mathrm{~cm}^{2}$.

\subsubsection{Wound Area Measurement}

The wound area was measured using a planimetry system. A 2-layered transparent film was placed on the wound, and the outline traced onto the film using a permanent marker. The layer of the film in contact with the wound was discarded. The top layer containing the tracing was retraced onto graph paper; the wound area was calculated.

After measurement, the wound contraction was expressed as the percentage change in the original wound area using the following Formula (1) [46]:

$$
\text { Wound contraction } \frac{(\text { Specific day wound area }) \cdot 100 \%}{\text { (Original wound area })}
$$

\subsubsection{Morpho-histology Research}

Morpho-histology research of excise samples of wound tissues was made on samples fixed in 10\% solution of neutral formalin. Then, the test material was washed in running water and dehydrated and serial processing in ethanol solutions with the increase in the concentration: $50 \%, 60 \%, 70 \%, 80 \%, 90 \%, 96 \%$, and $100 \%$ for $40 \mathrm{~min}$ in each solution. Dehydrated samples were initially soaked in xylene for $30 \mathrm{~min}$ and then in paraffin within $2 \mathrm{~h}$. In the final stage, the samples were poured with molted paraffin. A sledge microtome (Chuvash State University named after I.N. Ulyanova, Russia) was used for getting paraffin block slices. The samples were colored by hematoxylin and eosin.

\subsubsection{Microcirculation Research}

Microcirculation was assessed quantitatively using the LAKK-02 (LASMA, Moscow, Russia). This device transmits continuous wave laser light $(30 \mathrm{~mW}, 890 \mathrm{~nm})$ and white light $(20 \mathrm{~W}, 500-900 \mathrm{~nm})$ to skin tissue near the wound, where it is scattered and collected on the skin surface with fibers of the probe. The movement of erythrocytes causes a Doppler shift, which in turn is detected by the laser light and analyzed by the LAKK-02, that is then computed and displayed as the blood flow velocity. The detected laser signal correlates with the number of moving erythrocytes in tissue and blood flow velocity for calculation microcirculation parameters, using such arbitrary (relative) units (arb. un.) as perfusion units (perf. un.). The rate of microcirculation (the microcirculation level), the regulatory activity of its components, and the degree of shunt path participation with an allowance for the frequency range intervals of the blood flow oscillations in the rats' microvessels were investigated $[47,48]$.

\subsubsection{Biological Analysis In Vitro}

In vitro biological analysis was performed using blood stabilized with sodium citrate. Erythrocytes were washed twice with $0.9 \% \mathrm{NaCl}$ by centrifugation for $10 \mathrm{~min}$ at $1600 \times \mathrm{g}$. The intensity of lipid peroxidation (LPO) was estimated by MDA level in plasma and erythrocytes following the methods by Uchiyama and Mihara [49]. Superoxide dismutase activity (EC 1.15.1.1) was measured in erythrocytes using inhibition of adrenaline autooxidation [50]. Catalase activity (EC 1.11.1.6) was determined by spectrophotometry based on the decomposition of hydrogen peroxide by the catalase [51]. The specific activity of the enzymes was calculated from the protein concentration analyzed by the modified Lowry method [52]. 


\subsubsection{Cytotoxicity Tests}

We used mouse fibroblast cell culture L929 (tissue culture collections of D.I. Ivanovsky Institute of Virology, Russia). The cells were cultured in Dulbecco's modified Eagle's medium (DMEM) (PanEko, Moscow, Russia) with 10\% fetal bovine serum (FBS bovine serum (FBS) (HyClone, Pittsburgh, PA, USA) and antibiotics (gentamycin). Conditions: 5\% $\mathrm{CO}_{2}, \mathrm{t}=37^{\circ} \mathrm{C}$, and $5 \%$ humidity in an MCO-170M incubator (Sanyo, Japan). Cells in the exponential growth phase were dispersed in a 96-well plate $\left(5 \times 10^{3}\right.$ cells/well) for $24 \mathrm{~h}$. Then, we added dispersions of studied wound dressings (BC-BDP, BC-ZnO NPs-BDP) or $\mathrm{BDP}$ into the fresh replaced medium for $24 \mathrm{~h}$ incubation at $37^{\circ} \mathrm{C}$. The control sample was the wells containing only the cells. The cytotoxicity was measured using the dimethyl thiazolyl diphenyl (MTT) assay method. The medium was replaced with a fresh one with a $5 \mathrm{mg} / \mathrm{mL}$ MTT solution. After $4 \mathrm{~h}$ incubation time, the medium was removed, $150 \mu \mathrm{L}$ dimethyl sulfoxide (DMSO) was added. The mixture was treated by ultrasound at $44 \mathrm{kHz}$ for $3 \mathrm{~min}$. The absorbance was measured on an EFOS 9305 microplate reader (Russia) at $492 \mathrm{~nm}$ with a reference wavelength of $620 \mathrm{~nm}$. Cell viability was determined as the ratio of the sample's absorbance to the control expressed as a percentage.

\subsection{Statistical Analysis}

Statistical data processing was performed by Statistica 6.0 software (StatSoft Inc., Tulsa, OK, USA). The normality of a distribution of results was shown using the Shapiro-Wilk test. The significance of differences between groups was assessed using Student's $t$-test and one-way analysis of variance (ANOVA). The differences were considered statistically significant at $p<0.05$.

\section{Results and Discussion}

3.1. Optimization of the Synthesis of ZnO NPs and Development of a Method for Designing Nanocomposites of $\mathrm{BC}$ and $\mathrm{ZnO} N \mathrm{Ns}_{\mathrm{s}}$

In this work, we used a sol-gel method for obtaining unprotected $\mathrm{ZnO} N P s$ exhibiting quantum-dots properties [41]. Protected ZnO NPs were obtained by synthesis from zinc acetate and lithium hydroxide in the presence of PEG 400 [42] and zinc nitrate and sodium hydroxide in the presence of trisamine.

Table 1 shows the sequence of preparation of various samples of nanocomposites of $\mathrm{BC}$ and $\mathrm{ZnO}$ NPs in film and powder form.

Table 1. Preparation procedure of BC (bacterial cellulose)-ZnO (nanoparticles) NPs composites.

\begin{tabular}{|c|c|c|c|}
\hline BC Type & 1 Step & 2 Step & 3 Step \\
\hline film & $\begin{array}{c}\text { soaking, } 3 \mathrm{~h} \text { in } 1 \% \\
\text { trisamine solution, then } 5 \\
\mathrm{~h} \text { in aq. solution of } \\
\mathrm{Zn}\left(\mathrm{NO}_{3}\right)_{2} \cdot 4 \mathrm{H}_{2} \mathrm{O}\end{array}$ & $\begin{array}{l}\text { BC film removing and } \\
\text { transfer into shallow } \\
\text { container with } 0.1 \mathrm{M} \\
\text { solution of } \mathrm{NaOH} \text { for } 10 \\
\text { min at } 50^{\circ} \mathrm{C}\end{array}$ & $\begin{array}{l}\text { rinse with distilled } \\
\text { water until the } \\
\text { composite } \mathrm{pH} \text { became } \\
\text { neutral, then drying }\end{array}$ \\
\hline film & $\begin{array}{l}\text { soaking, } 3 \mathrm{~h} \text { in } 1 \% \\
\text { trisamine solution or } \\
\text { DDS-Na or } \\
\text { benzalkonium chloride } \\
\text { for } 30 \mathrm{~min}\end{array}$ & $\begin{array}{l}\text { BC film removing and } \\
\text { transfer into shallow } \\
\text { container, then spraying } \\
\text { of } \mathrm{ZnO} \mathrm{NPs} \\
\text { water-alcohol dispersion } \\
\text { onto film surface }\end{array}$ & drying \\
\hline powder & $\begin{array}{c}\text { soaking, } 3 \mathrm{~h} \text { in } 1 \% \\
\text { trisamine solution or } \\
\text { DDS-Na or } \\
\text { benzalkonium chloride } \\
\text { for } 30 \mathrm{~min} \text {, sonification }\end{array}$ & $\begin{array}{l}\text { transfer into vessel, then } \\
\text { adding of } \mathrm{ZnO} \text { NPs } \\
\text { water-alcohol dispersion, } \\
\text { then sonification }\end{array}$ & $\begin{array}{l}\text { separation solid phase, } \\
\text { rinse with distilled } \\
\text { water until the } \\
\text { composite pH became } \\
\text { neutral, then drying }\end{array}$ \\
\hline
\end{tabular}


We studied BC-ZnO NPs composite films containing 1-30\% of ZnO NPs. Powder $X$-ray diffractometry (PXRD) analysis was performed after drying samples stored in a desiccator.

The average particle size (diameter) was determined by PXRD according to the Scherrer Formula (2):

$$
\mathrm{D}=\frac{k \times \lambda}{\beta \times \cos \theta},
$$

where $k$ is the dimensionless particle shape factor, taken as $0.89 ; \lambda$ is the wavelength of $X$-ray radiation $(0.154178 \mathrm{~nm}) ; \beta$ is the width of the reflex at half height in rad; and $\theta$ is the scattering angle in rad.

The data in Figure $1 \mathrm{a}$ and identification by the database show that the obtained protected $\mathrm{ZnO}$ NPs and ZnO NPs immobilized into the BC matrix had a hexagonal wurtzite shape with an average size of 11.5-18.71 nm (Table 2).

The effect of surfactants (cationic benzalkonium chloride or anionic sodium dodecyl sulfate) on the structure of the BC-ZnO NPs composites was insignificant. In all cases, a crystal hexagonal structure of wurtzite was formed in the BC matrix. A weak effect of cationic and anionic surfactants on the polymorphism of calcium carbonate (polymorphcalcite) during its precipitation on BC was noted in [53]. On the other hand, these authors obtained crystals of various shapes depending on the type and concentration of surfactants.

Changes in the nanocomposite were observed for the BC structure having an initial average size of 4-6 $\mathrm{nm}$ (Figures 1 and 2, Table 2). The peak position with a maximum at $2 \theta=22.96-23.08$ degrees changed insignificantly, but the shape and position of the other two peaks inherent in crystalline $\mathrm{BC}$ had a different appearance. It can be assumed that the change in the structure of $\mathrm{BC}$ in the presence of $\mathrm{ZnO}$ NPs is due to the higher elasticity of BC (the ability of cellobiose units in the form of a "chair" to change their conformation) and smaller size compared to ZnO NPs.
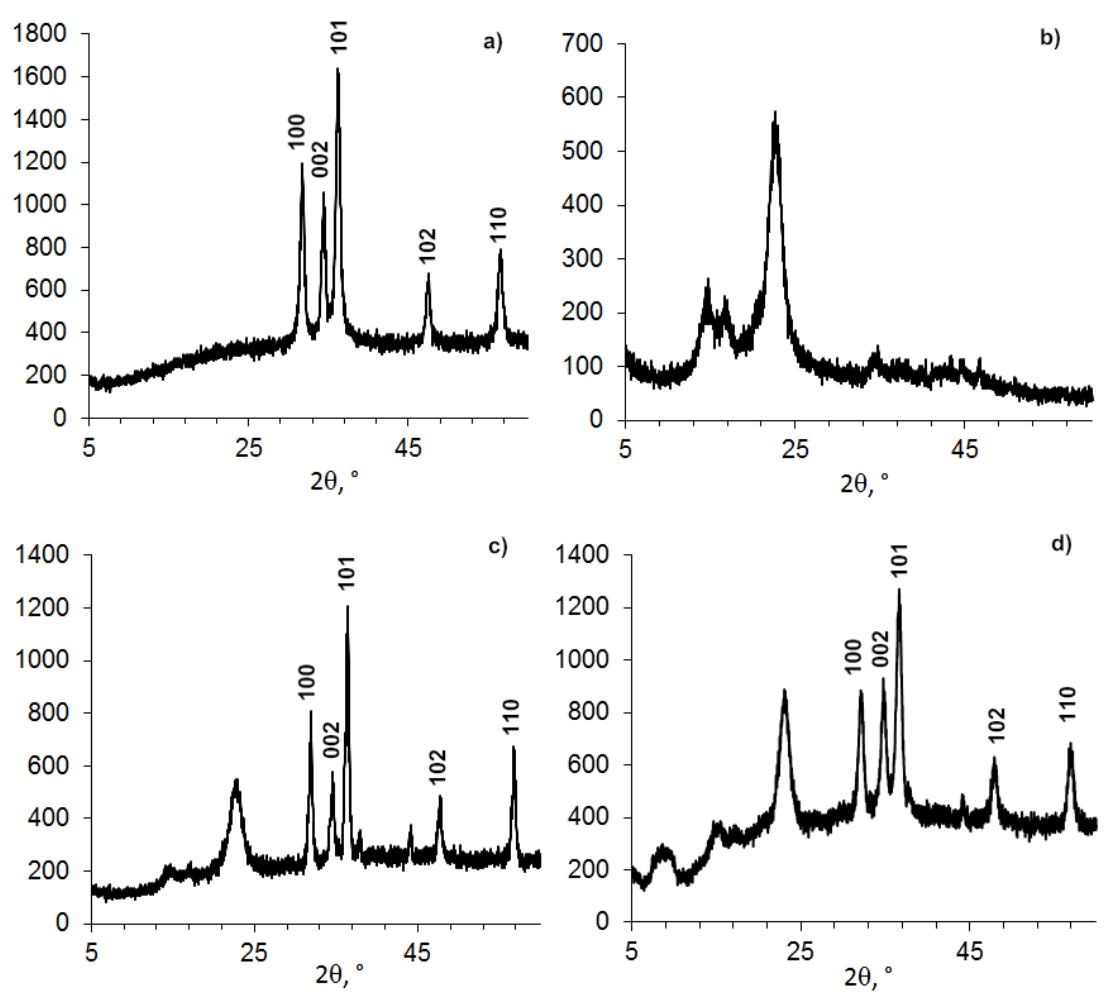

Figure 1. Powder XRD patterns of BC-ZnO samples: (a) ZnO NPs-PEG, (b) BC powder, (c) BC film-ZnO NPs, and (d) BC powder-ZnO NPs. 
Table 2. Data of powder XRD patterns of BC-ZnO NPs samples (Figure 1).

\begin{tabular}{|c|c|c|c|c|c|}
\hline $\begin{array}{l}\text { Figure } \\
\text { Number }\end{array}$ & Sample & $\begin{array}{l}\text { Composition } \\
\text { (Treatment }^{1} \text { ) }\end{array}$ & 20, Degree & $\mathrm{D}, \mathrm{nm}$ & $\begin{array}{l}\text { Structure } \\
\text { Signal }\end{array}$ \\
\hline $\mathrm{a}$ & 1 & $\begin{array}{c}\mathrm{ZnO} \\
\text { NPs-PEG }\end{array}$ & $\begin{array}{l}36.18 \\
47.60 \\
56.54\end{array}$ & $\begin{array}{l}14.040 \\
11.562 \\
12.285\end{array}$ & $\begin{array}{c}\mathrm{ZnO} \\
\text { (wurtzite) }\end{array}$ \\
\hline $\mathrm{b}$ & 2 & $\mathrm{BC}$ & 22.96 & 4.749 & $\mathrm{BC}$ \\
\hline c & 3 & $\begin{array}{c}\mathrm{BC} \\
(\text { film)-ZnO } \\
\text { NPs }\end{array}$ & $\begin{array}{l}22.68 \\
36.38 \\
47.80 \\
56.84\end{array}$ & $\begin{array}{c}4.601 \\
18.719 \\
18.284 \\
15.725\end{array}$ & $\begin{array}{c}\mathrm{ZnO} \\
\text { (wurtzite) }\end{array}$ \\
\hline $\mathrm{d}$ & 4 & BC-ZnO NPs & $\begin{array}{l}23.08 \\
36.64\end{array}$ & $\begin{array}{c}5.520 \\
10.620\end{array}$ & $\begin{array}{c}\mathrm{BC} \\
\mathrm{ZnO} \\
\text { (wurtzite) }\end{array}$ \\
\hline- & - & $\mathrm{ZnO} \mathrm{NPs}^{2}$ & $\begin{array}{l}31.76 \\
34.36 \\
36.22\end{array}$ & $\begin{array}{l}11.600 \\
17.500 \\
11.700\end{array}$ & $\begin{array}{c}\mathrm{ZnO} \\
\text { (wurtzite) }\end{array}$ \\
\hline
\end{tabular}

${ }^{1}$ Ultrasound treatment. ${ }^{2}$ Data of our samples protected by betulin diphosphate (BDP) were published in [3].

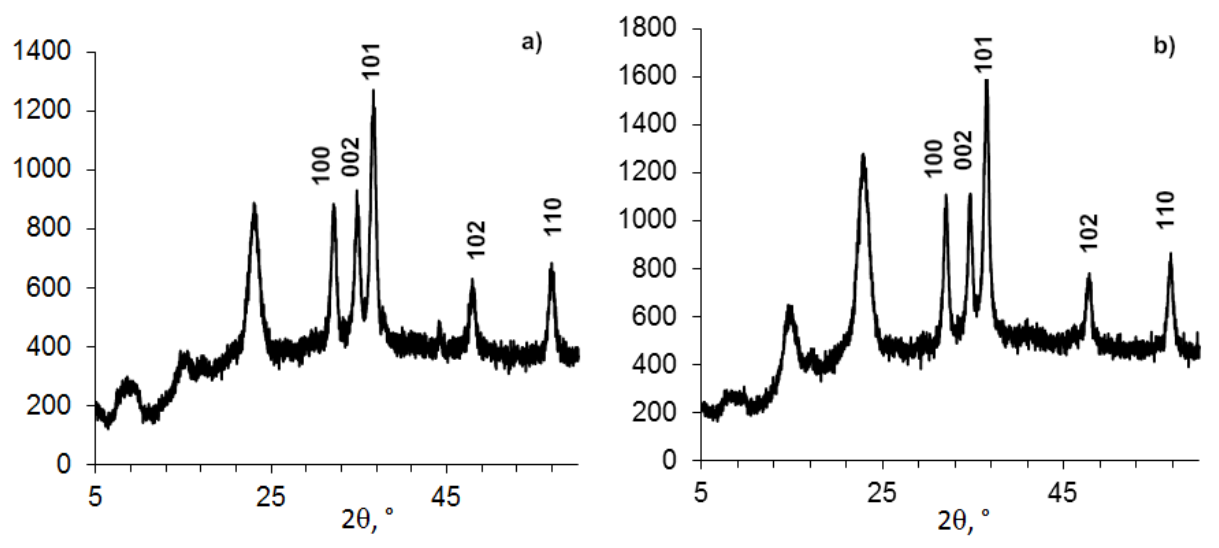

Figure 2. Powder XRD patterns of compositions (BC $0.5 \mathrm{~g}+\mathrm{ZnO}$ NPs $0.15 \mathrm{~g}$ ) samples, formed in different conditions in the presence of tris (a) or DDS-Na (b).

The conditions (time, alkaline volume, reagent addition sequence) are indicated in the Table 3.

Table 3. The dependence of the structure of $\mathrm{BC}-\mathrm{ZnO}$ NPs composition (23\% of $\mathrm{ZnO}$ ) on formation conditions (Figure 2).

\begin{tabular}{|c|c|c|c|c|c|c|c|}
\hline \multirow{2}{*}{$\begin{array}{l}\text { Figure } \\
\text { Number }\end{array}$} & \multirow{2}{*}{ Sample } & \multirow{2}{*}{ Procedure } & \multicolumn{2}{|c|}{$\begin{array}{l}\text { ZnO NPs Content, } \mathrm{g} \text { in } 0.5 \mathrm{~g} \\
\text { BC }(\%), n=3\end{array}$} & \multirow{2}{*}{$\begin{array}{c}2 \theta, \\
\text { Degree }\end{array}$} & \multirow{2}{*}{$\mathrm{D}, \mathrm{nm}$} & \multirow{2}{*}{ Signal } \\
\hline & & & Added & $\begin{array}{l}\text { Found } \\
\text { (AAS) }\end{array}$ & & & \\
\hline a & 5 & $\begin{array}{l}\text { 1. Preparation of } \mathrm{ZnO} N \text { Ns dispersion in } 1 \% \text { tris } \\
\text { aqueous solution }(25 \mathrm{~mL}) \text { at } \mathrm{pH} 10 \text {. } \\
\text { 2. Ultrasound treatment } \\
\text { 3. } \mathrm{BC} \text { addition to dispersion under sonification } \\
\text { 4. Storage for } 1 \mathrm{~h} \\
\text { 5. Filtration and drying at } 120^{\circ} \mathrm{C}\end{array}$ & $\begin{array}{c}0.150 \\
(23.0 \pm 0.1 \%)\end{array}$ & $(26.0 \pm 0.2) \%$ & 22.96 & 11.19 & $\mathrm{ZnO}$ \\
\hline $\mathrm{b}$ & 6 & $\begin{array}{l}\text { 1. Preparation of } \mathrm{BC} \text { water-ethanol dispersion in the } \\
\text { presence of } 0.01 \% \text { DDS-Na aqueous solution }(0.1 \mathrm{~mL}) \\
\text { at } \mathrm{pH} 10 \text {. } \\
\text { 2. Ultrasound treatment } \\
\text { 3. ZnO NPs addition to dispersion under sonification } \\
\text { 4. Storage for } 1 \mathrm{~h} \\
\text { 5. Filtration and drying at } 120^{\circ} \mathrm{C}\end{array}$ & $\begin{array}{c}0.150 \\
(23.0 \pm 0.1 \%)\end{array}$ & $(22.6 \pm 0.2) \%$ & 22.74 & 12.28 & $\mathrm{ZnO}$ \\
\hline
\end{tabular}


This influence of $\mathrm{ZnO}$ NPs in the composition on the BC structure is indirectly confirmed by the study of composites BC-ZnO NPs, in which the concentration of ZnO NPs increases from $3.8 \%$ to $23.0 \%$ (Figure 3, Table 4). The BC peaks at a high concentration of $\mathrm{ZnO}$ NPs at small angles ( $2 \theta$ from $5^{\circ}$ to $15^{\circ}$ ) appear indistinct.
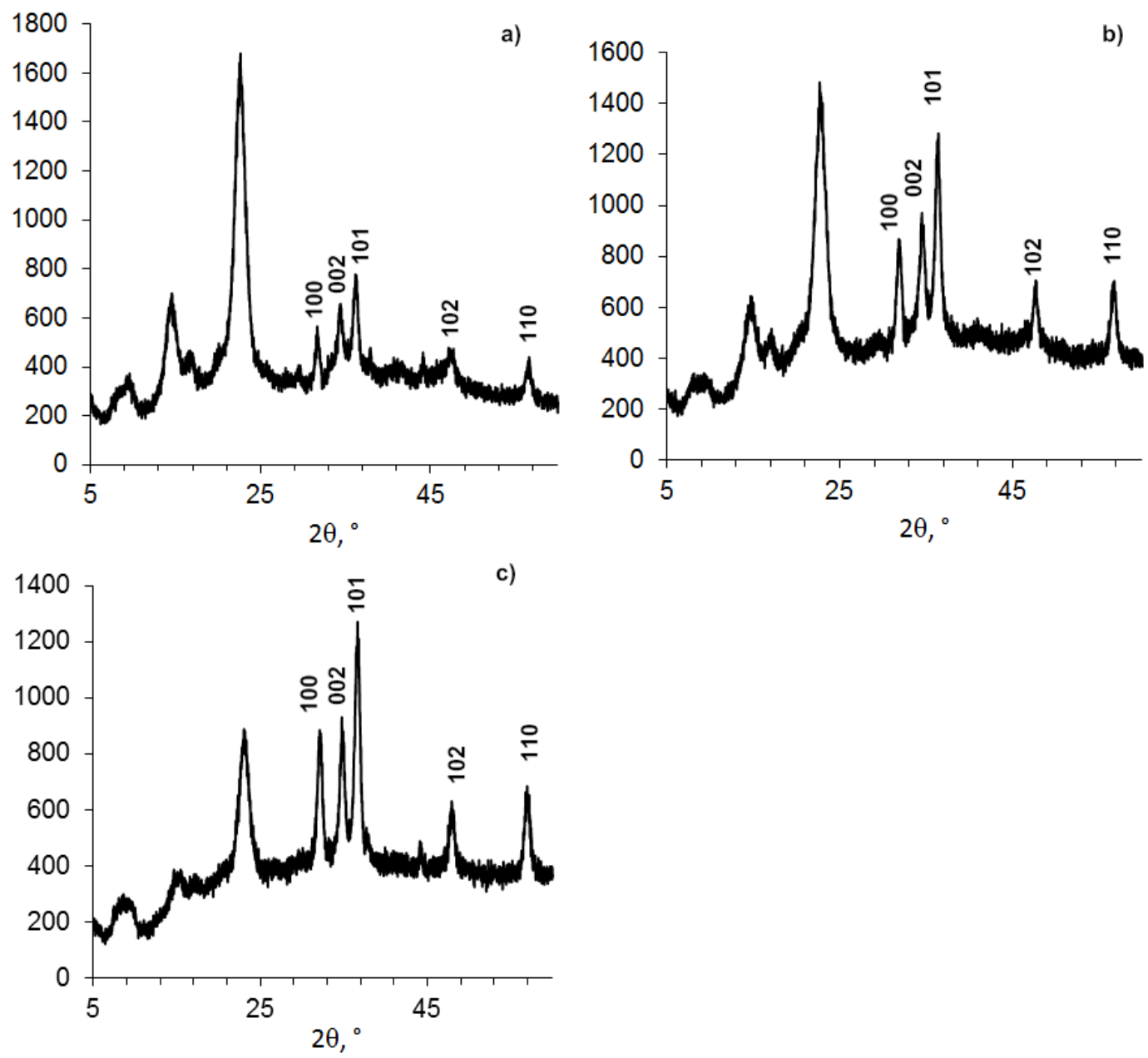

Figure 3. Powder XRD patterns of compositions (BC-ZnO NPs) samples, with concentrations of ZnO NPs: a). $6.6 \%$; b). $16.9 \%$; c). $26 \%$.

Table 4. Data of Figure 3.

\begin{tabular}{|c|c|c|c|c|c|c|}
\hline \multirow{2}{*}{$\begin{array}{l}\text { Figure } \\
\text { Number }\end{array}$} & \multirow[t]{2}{*}{ Sample } & \multicolumn{2}{|c|}{$\begin{array}{l}\text { ZnO NPs Content, } \mathrm{g} \text { in } 0.5 \mathrm{~g} \text { BC } \\
(\%), n=3\end{array}$} & \multirow[t]{2}{*}{ 2ө, Degree } & \multirow[t]{2}{*}{$\mathrm{D}, \mathrm{nm}$} & \multirow[t]{2}{*}{ Signal } \\
\hline & & Added & Found (AAS) & & & \\
\hline a & 7 & $0.025(3.8 \%)$ & $(6.6 \pm 0.2) \%$ & $\begin{array}{l}22.64 \\
36.32\end{array}$ & $\begin{array}{c}6.33 \\
13.49\end{array}$ & $\begin{array}{c}\mathrm{BC} \\
\mathrm{ZnO}\end{array}$ \\
\hline $\mathrm{b}$ & 8 & $0.075(11.5 \%)$ & $(16.9 \pm 0.2) \%$ & $\begin{array}{l}22.68 \\
36.42\end{array}$ & $\begin{array}{c}5.37 \\
10.62\end{array}$ & $\begin{array}{c}\mathrm{BC} \\
\mathrm{ZnO}\end{array}$ \\
\hline c & 5 & $0.150(23.0 \%)$ & $(26 \pm 0.2) \%$ & $\begin{array}{l}22.96 \\
36.64\end{array}$ & $\begin{array}{c}5.88 \\
11.19\end{array}$ & $\begin{array}{c}\mathrm{BC} \\
\mathrm{ZnO}\end{array}$ \\
\hline
\end{tabular}

The immobilization of betulin diphosphate (BDP) in $\mathrm{BC}$ can be made by swelling the cellulose in either an alcoholic BDP solution or an aqueous BDP sodium salt solution in the molar ratio trisamine: $\mathrm{BDP}=4: 1$. After transferring the obtained $\mathrm{BC}-\mathrm{BDP}$ films into a flat container, they were dried. To obtain complex combined composites BC-ZnO NPs-BDP, a 
suspension of an aqueous-alcoholic solution of ZnO NPs was sprayed onto the resulting BC-BDP film.

Powder X-ray diffractometry data are presented in Figure 4 and Table 5.

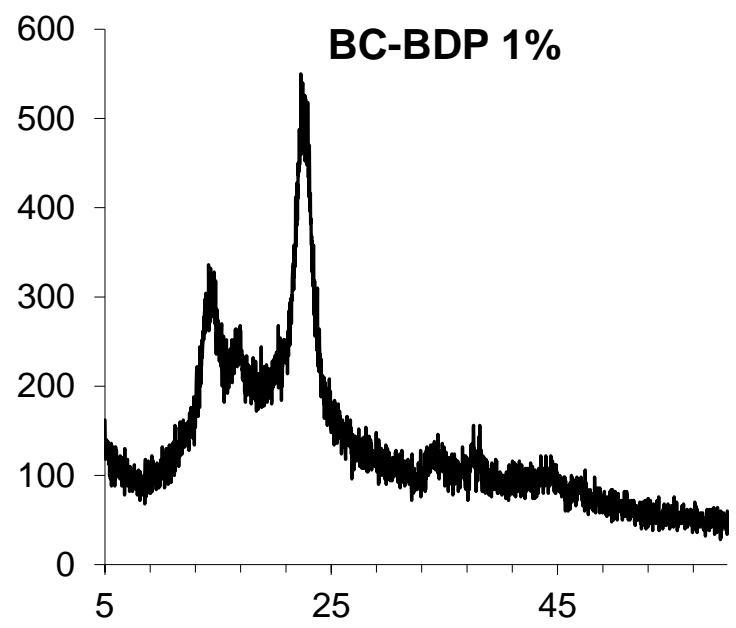

(a)

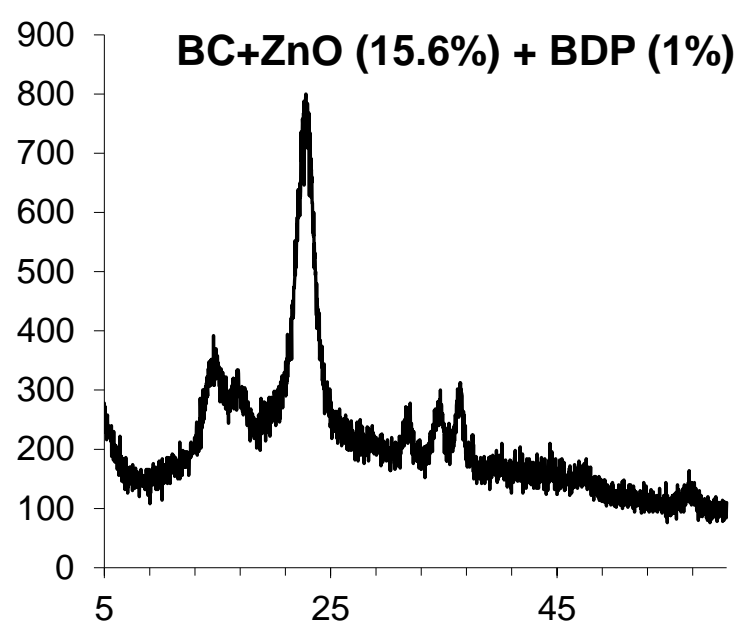

(b)

Figure 4. Powder XRD patterns of BC compositions: (a). BC-BDP (1\%); (b). BC (DDS-Na 0.01\%) + ZnO NPs+ BDP.

Table 5. Data of Powder XRD patterns of BC-ZnO NPs samples (Figure 4).

\begin{tabular}{cccccc}
\hline Figure Number & Sample & Composition (Treatment ${ }^{\mathbf{1}}$ ) & 20, Degree & D, nm & Signal \\
\hline $\mathrm{a}$ & 9 & $\mathrm{BC}-\mathrm{BDP}(1 \%)$ & 22.48 & 6.25 & $\mathrm{BC}$ \\
$\mathrm{b}$ & \multirow{2}{*}{10} & $\mathrm{BC}(\mathrm{DDS}-\mathrm{Na} 0.01 \%)+\mathrm{ZnO}$ NPs & 22.64 & 4.40 & $\mathrm{BC}$ \\
& & + BDP & 36.20 & 12.16 & $\mathrm{ZnO}$ \\
\hline
\end{tabular}

${ }^{1}$ Ultrasound treatment.

ZnO NPs were treated with BDP water:ethanol (1:1) previously for the decrease of possible aggregation. The zeta potential of $\mathrm{ZnO} N P s$ was equal to $+15.9 \mathrm{mV}$ in water:ethanol (1:1) solution but zeta potential of $\mathrm{ZnO} N$ Ps modified by BDP was equal to $-41.2 \mathrm{mV}$ in water:ethanol (1:1) solution. The zeta potential changes can be explained by ionization of BDP phosphate groups in water:ethanol (1:1) solution ( $\mathrm{pH}$ near 3.75) (Figure 5).
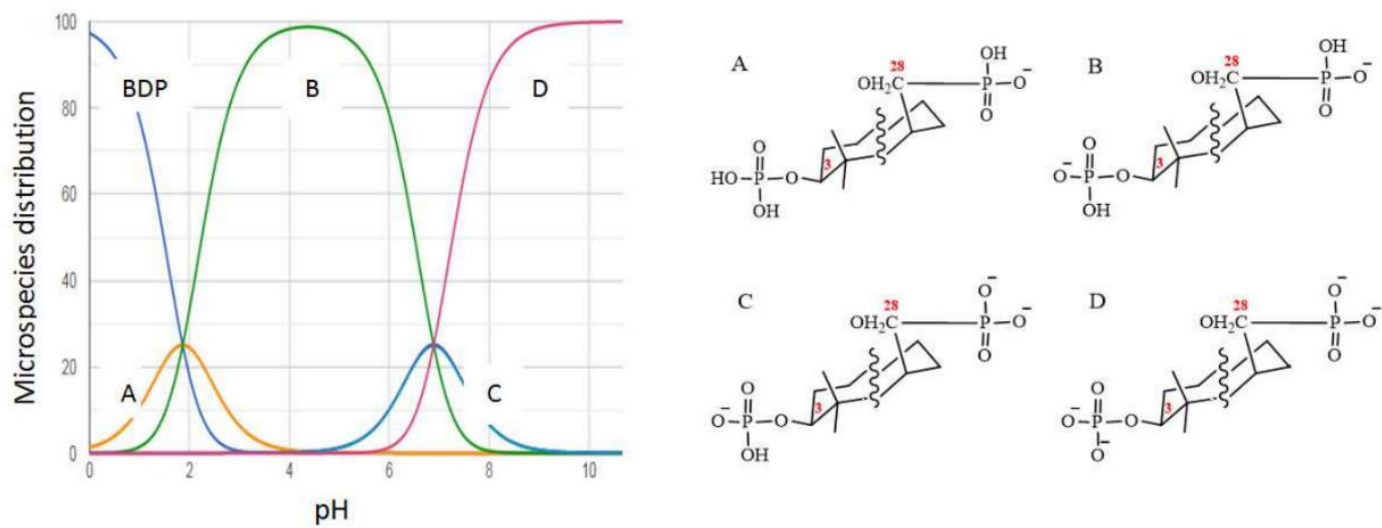

Figure 5. The dependence of BDP microspecies distributions (\%) on pH calculated using Chemicalize program [54].

It was shown by electrospray ionization mass spectrometry at $180{ }^{\circ} \mathrm{C}$ in methanol that the molecular isotopic mass of BDP is equal to 602.314. It is seen that the spectrum 
contains one peak corresponding to an ion with a molecular weight of 601.3067 (the peak itself and the isotope distribution for this ion are shown in Figure S3). Consequently, BDP ionization occurs by eliminating only one proton in methanol, but two or more protons may be eliminated in an aqueous solution.

Schematic representation of the BDP adsorption onto ZnO NPs' surface from water:alcohol solution leads to the generation of negative charge of ZnO NPs' surface as shown in Figure 6. Observed zeta potential value after BDP adsorption onto ZnO NPs surface suggests that aggregation is difficult.

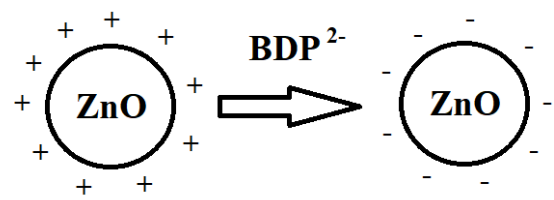

Figure 6. Schematic representation of the formation of negative charge.

Similar formation of negative charge onto ZnO NPs' surface and an increase of dispersion stability in the presence of citric acid were described in the work [55].

If $\mathrm{BC}$ was previously wetted by BDP water:alcohol solution and then $\mathrm{ZnO}$ NPs are loaded into the BC-BDP system, the positive charge of $\mathrm{ZnO}$ NPs will be changed to negative, which will prevent agglomeration of colloid particles.

SSAs of ZnO NPs without BDP protection are equal to $35.2 \pm 1.3 \mathrm{~m}^{2} \cdot \mathrm{g}^{-1}$. SSAs of $\mathrm{ZnO}$ NPs with BDP protection are equal to $40.5 \pm 0.9 \mathrm{~m}^{2} \cdot \mathrm{g}^{-1}$.

Figure 7 shows that the SEM image of ZnO NPs modified by BDP (ZnO NPs-BDP) is similar to the SEM image of ZnO NPs. Nanoparticles sizes calculated by PXRD of ZnO NPs are close to ZnO NPs-BDP sizes (Tables 2 and 5). This fact characterizes the absence of nanoparticles aggregation after modification.

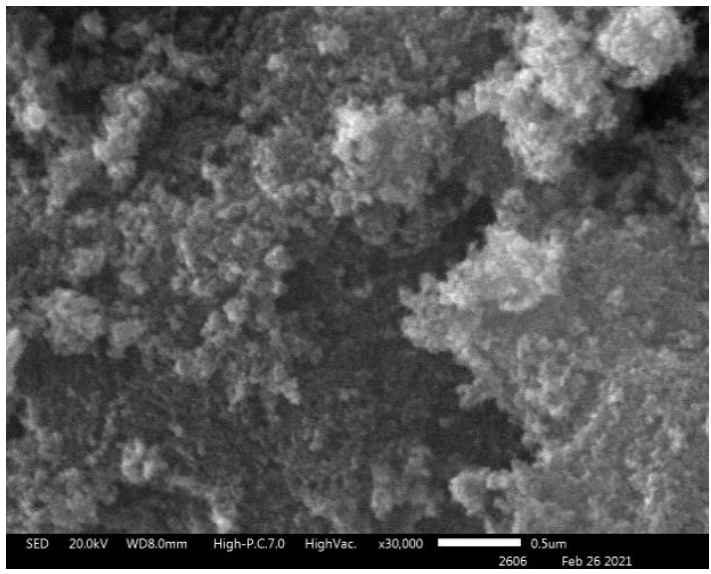

(a)

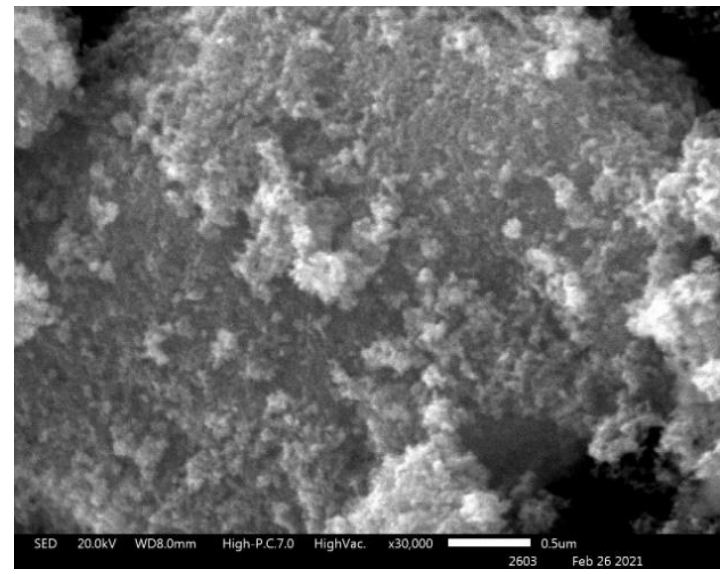

(b)

Figure 7. Scanning electron microscopy (SEM) images of ZnO NPs (a) and ZnO NPs modified by BDP (b), $\times 30,000$.

The composition and structure of the composites based on BC were studied by IR spectral analysis, atomic absorption spectrophotometry, and complexometric titration of zinc oxide (Table 6, Figure S4). 
Table 6. Composition and FTIR spectral characteristics of ZnO NPs and bacterial cellulose samples (Figure S4).

\begin{tabular}{|c|c|c|c|}
\hline \multirow[b]{2}{*}{ Composition } & \multicolumn{2}{|c|}{$\mathrm{ZnO}, \%$} & \multirow{2}{*}{$\begin{array}{l}v, \mathrm{sm}^{-1} \\
420-500\end{array}$} \\
\hline & Ad. & $\begin{array}{c}\text { Found, } \\
n=3\end{array}$ & \\
\hline $\mathrm{ZnO}$ NPs & 100 & 100 & 450-467 (v ZnO NPs) \\
\hline $\mathrm{BC}$ & - & - & $\begin{array}{l}596,620,642,665,899,1037,1062,1200, \\
2366,2900\left(\mathrm{CH}, \mathrm{CH}_{2}\right), 3347,3355(\mathrm{OH})\end{array}$ \\
\hline $\mathrm{BC}-\mathrm{ZnO} \mathrm{NPs}$ & 16.67 & $17.8 \pm 0.2$ & $450-470$ \\
\hline $\begin{array}{c}\mathrm{BC}+0.01 \% \text { DDS-Na }+ \\
\mathrm{ZnO} \text { NPs }\end{array}$ & 16.67 & $16.2 \pm 0.3$ & 473 (ZnO NPs), \\
\hline
\end{tabular}

FTIR spectrum of BC-ZnO NPs composite has bands of ZnO NPs $\left(\vee 450 \mathrm{~cm}^{-1}\right)$, intense $\mathrm{C}-\mathrm{O}$ (hydroxyl) bands of $\mathrm{BC}\left(v 1037-1200 \mathrm{~cm}^{-1}\right)$ and intense $\mathrm{CH}, \mathrm{CH}_{2}$ bands $\left(v 2900 \mathrm{~cm}^{-1}\right)$. Moreover, the spectrum contains an intense band of stretching vibrations of $\mathrm{OH}$ groups in the region of $3355 \mathrm{~cm}^{-1}$. It can be noted that immobilization of BDP into the BC matrix does not change the shape of the PXRD patterns. In contrast, the inclusion of ZnO NPs in the composition significantly affected the spectra. Probably, BDP can adsorb on the surface of ZnO NPs due to the chemisorption binding of phosphate groups of BDP with $\mathrm{Zn}^{2+}$ ions. Besides, the "chair" conformational structures in the triterpenoid and cellulose unit promote a softer introduction of the triterpenoid into the BC structure (Figure 8).

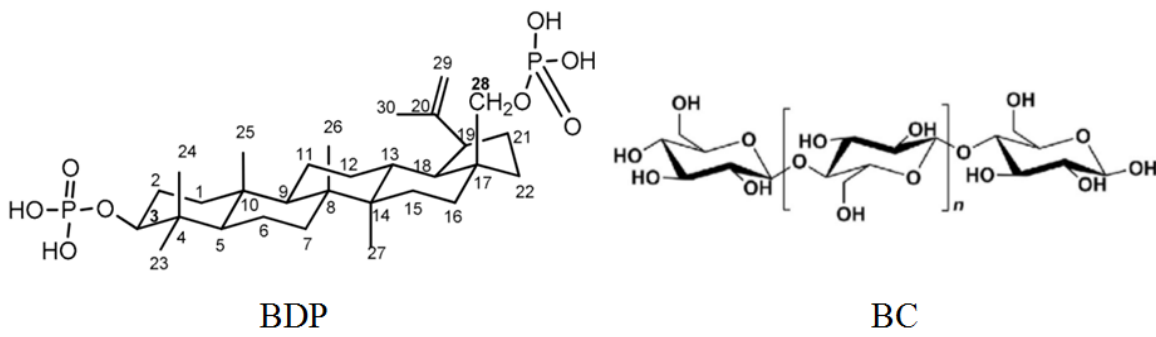

Figure 8. Formulas of betulin-3,28-diphosphate (BDP) and cellulose unit.

The spectra of $\mathrm{ZnO}$ NPs contain an absorption band characteristic of ZnO NPs in the region of 450-500 $\mathrm{cm}^{-1}$ and hydrated $\mathrm{Zn}\left(\mathrm{H}_{2} \mathrm{O}\right)_{2}{ }^{2+}$ ions in the region of $890-850 \mathrm{~cm}^{-1}$, as well as an absorption band corresponding to hydroxyl groups in the region of $3449-3377 \mathrm{~cm}^{-1}$. IR spectra of PEG-stabilized ZnO NPs have absorption bands characteristic of PEG (Figure S4).

The spectrum of $\mathrm{BC}$ contains bands of the monomeric unit of cellobiose $\left(v, \mathrm{~cm}^{-1}\right)$ : $596,620,642,665,744,890$, and $990\left(7 \mathrm{CH}-\mathrm{OH}, 1 \mathrm{CH}_{2}-\mathrm{OH}\right)$ [56]. The first five bands are moderately expressed, but the bands' characteristic of stretching vibrations of alcohol C-O groups in the region of $1037-1200 \mathrm{~cm}^{-1}$ and stretching vibrations of $\mathrm{CH}$ and $\mathrm{CH}_{2}$ groups in the region of $3000-2900 \mathrm{~cm}^{-1}$ are intensely expressed. Furthermore, the band of stretching vibrations of $\mathrm{OH}$-groups in the region of $3355 \mathrm{~cm}^{-1}$ is intensely expressed.

In the BC-ZnO NPs composite, the determining sign of zinc oxide nanoparticles' appearance is the absorption band in the region of $450-470 \mathrm{~cm}^{-1}$. In the BC-ZnO NPs-BDP composite, in addition to the BC bands, a set of bands inherent in BDP appears (Figure S5).

The photoluminescence (PL) spectra of dispersions of $\mathrm{ZnO}$ NPs contained a weak blue emission absorption band $\lambda_{\mathrm{em}}=372 \mathrm{~nm}$, which characterizes the edge emission of quantum dots and the onset of ultraviolet absorption (Figure S2) [3]. In the UV spectra of either aqueous, alcohol, or both dispersions of ZnO NPs in the region of 340-370 nm, a band of abnormal light absorption (plasmon effect) appeared, which is characteristic of nanoparticles (Figure S2) [3].

Figure 9 shows that $\mathrm{BC}$ and $\mathrm{BC}-\mathrm{ZnO}$ NPs-BDP hydrogels have different structures of nanocomposites after drying. 


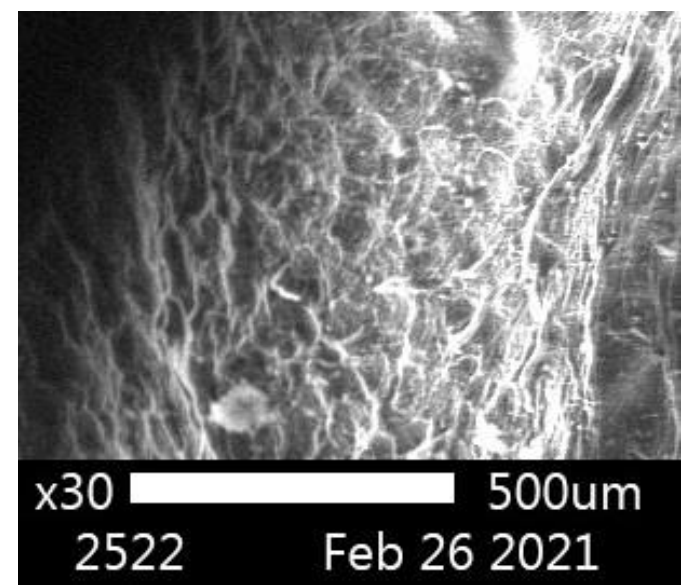

(a)

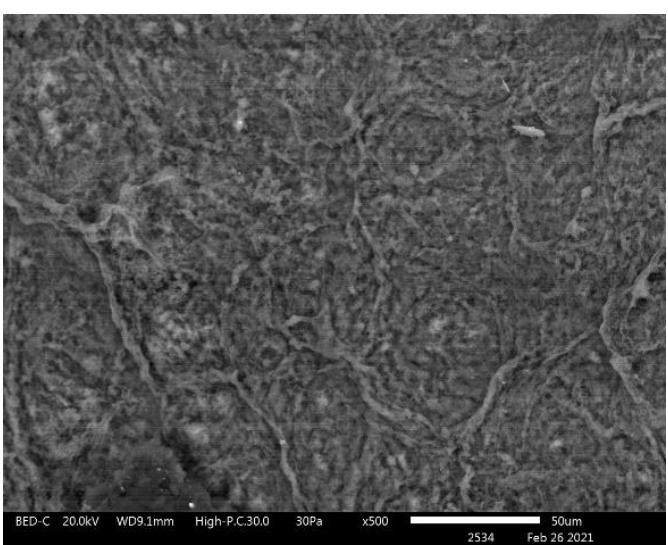

(c)

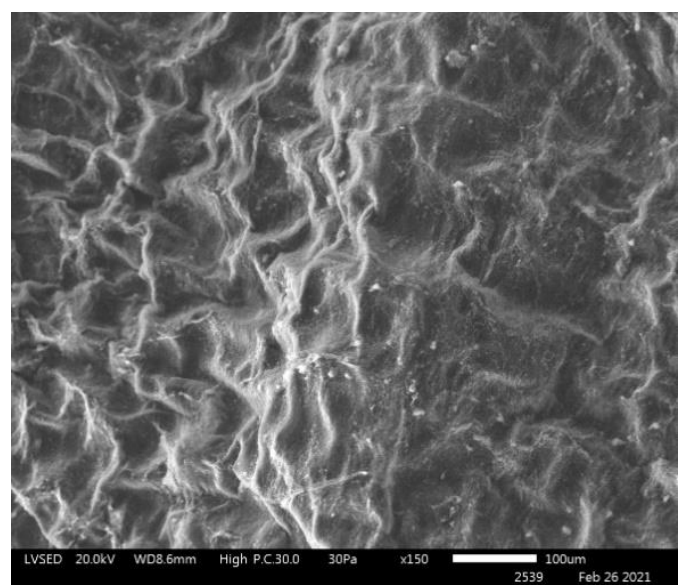

(b)

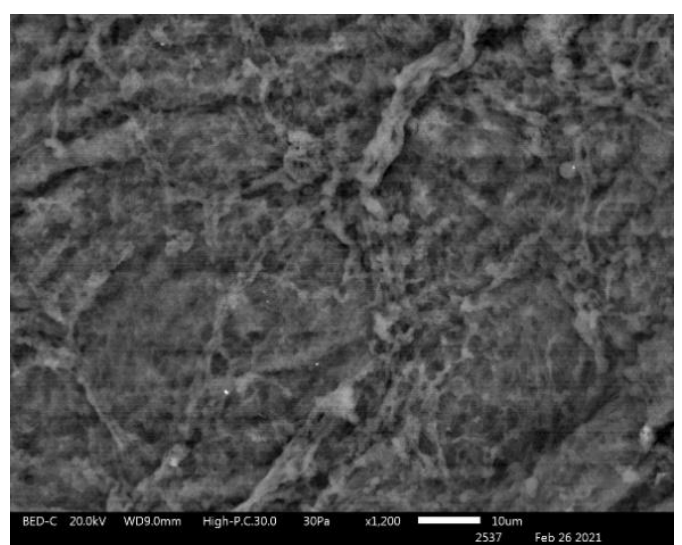

(d)

Figure 9. SEM images: BC hydrogel film $\times 30$ (a) and $\times 150$ (b); BC-ZnO NPs-BDP hydrogel film $\times 500(\mathbf{c})$ and $\times 1200(\mathbf{d})$.

Thus, our results (PXRD, IR, UV, and PL spectroscopy) allow us to conclude that the composite material obtained based on bacterial cellulose contains zinc oxide nanoparticles.

Immobilization of BDP and ZnO NPs in BC without distorting the original structure of BDP, which activates collagen synthesis in the wound [3], is a prerequisite for using these composites as wound dressings.

\subsection{Zinc Ions Release from BC-ZnO NPs-BDP Nanocomposite Films}

Assay of zinc ions released from BC-ZnO NPs-BDP nanocomposite films is important to understand the consequent toxicology of composites. The application of ZnO NPs containing composites in burn-wound healing might result in some health hazards of nanoparticles or free ions released in high quantity. The assay of zinc ions released from BC-ZnO NPs-BDP was estimated in water in Franz vertical diffusion cells (Figure S6) using the AAS or Inductively coupled plasma mass spectrometry (ICP) methods. Figure 10 shows a very small amount of zinc ions released during studied period. Release of zinc ions increased slowly with time and reached $1.56 \mathrm{ppm}$ after day 14 of study. This fact is similar to results of work [15]. This slow release may be due to strong interaction of ZnO NPs with BDP being hydrophobic particles in a BC matrix. 


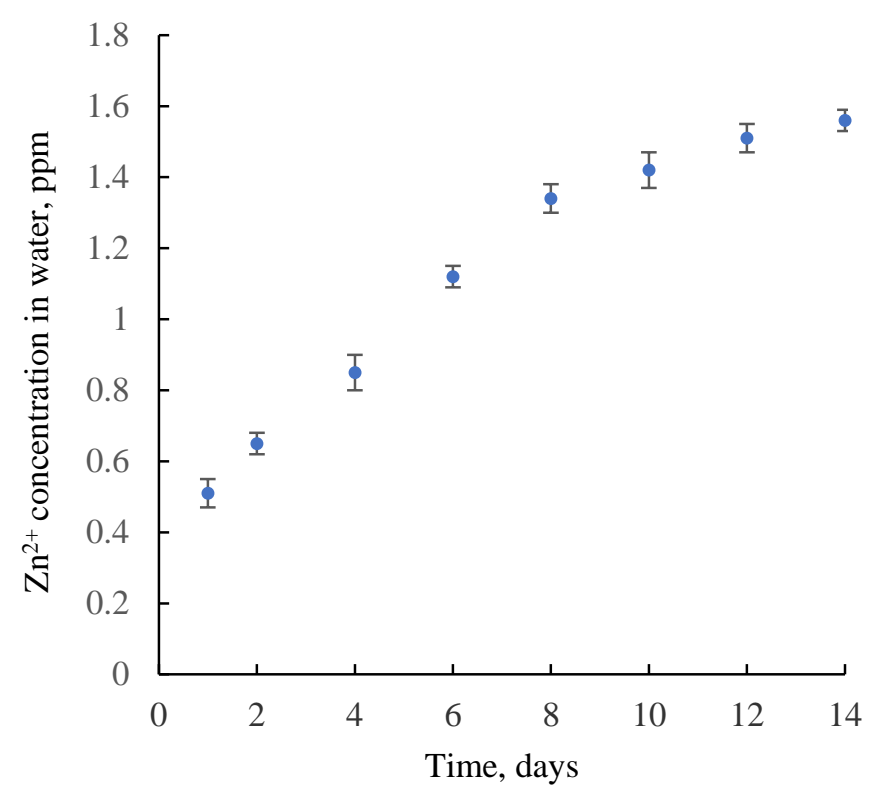

Figure 10. The assay of zinc ions released from BC-ZnO NPs-BDP nanocomposite films as membrane in water as a function of time using Franz vertical diffusion cells.

\subsection{Cell Viability under the Action of Wound Dressings and Their Biodegradability}

Cytotoxicity was estimated according to article [57] using the MTT test (Table 7). It has been shown that the influence of BDP, BC-BDP, and BC-ZnO NPs-BDP on cell viability was insignificant.

Table 7. Cell viability under the action of dispersions of studied wound dressings (BC-BDP, BC-ZnO NPs-BDP) and BDP $(n=3, p<0.01)$.

\begin{tabular}{|c|c|c|c|c|}
\hline \multirow{2}{*}{$\begin{array}{l}\text { Concentration of Studied } \\
\text { Dispersion, } \mu \mathrm{g} \cdot \mathrm{mL}^{-1}\end{array}$} & \multicolumn{4}{|c|}{ Cell Viability, \% of Control (Cells Only) } \\
\hline & BC & BDP & BC-BDP & $\begin{array}{c}\text { BC-ZnO } \\
\text { NPs-BDP }\end{array}$ \\
\hline 0 & $101.0 \pm 3.9$ & $100.9 \pm 2.0$ & $100.4 \pm 5.1$ & $99.3 \pm 4.5$ \\
\hline 12.5 & $102.2 \pm 3.1$ & $94.0 \pm 3.1$ & $105.2 \pm 3.3$ & $101.2 \pm 3.3$ \\
\hline 25.0 & $105.8 \pm 1.7$ & $92.9 \pm 1.8$ & $102.6 \pm 2.8$ & $109.4 \pm 5.2$ \\
\hline 50.0 & $104.0 \pm 7.3$ & $105.3 \pm 8.4$ & $93.8 \pm 2.1$ & $103.5 \pm 1.0$ \\
\hline 100.0 & $110.3 \pm 3.6$ & $109.2 \pm 2.1$ & $107.7 \pm 6.3$ & $105.4 \pm 5.9$ \\
\hline
\end{tabular}

The biodegradability of $\mathrm{BC}$ may be varied depending on study conditions of degradation. Wang B. et al. [58] showed that BC biodegrades by cellulase in simulated body fluid in vitro and has compatibility in vivo. Their results demonstrate that the $\mathrm{BC}$ material had good in vitro and in vivo compatibility in the presence of cellulase. On the other hand, bacterial cellulose is stable in the absence of cellulase, and other factors induced hydrolysis of a linear chain of $\beta(1 \rightarrow 4)$ linked D-glucose units [59].

We showed that BC-ZnO NPs-BDP, BC-ZnO NPs, BC-BDP, and BC films placed into $0.9 \% \mathrm{NaCl}$ solution for 21 days did not change $\mathrm{pH}$ value $(\mathrm{pH} 7.4 \pm 0.2)$. We propose that $\mathrm{pH}$ value is stable during burn wound treatment by studied films when a $0.9 \% \mathrm{NaCl}$ solution wets wound dressings.

3.4. Study of the Healing of a Thermal Burn Wound in an Experiment on Rats Treated with Agents Based on Bacterial Cellulose

BC-ZnO NPs-BDP films were closed on both sides with parchment and sealed in cellophane envelopes for biological studies.

A pharmaceutical composition with high wound healing activity containing ZnO NPs of a similar nature and size (wurtzite, $10-20 \mathrm{~nm}$ ) was chosen as a reference drug [3]. The 
pharmaceutical composition, made in the oleogel form, consists of zinc oxide nanoparticles $(5 \%)$, betulin $(5 \%)$, betulin diphosphate $(0.01 \%)$, and sunflower oil (up to $100 \%)$.

Four groups of animals were studied:

1. BC-ZnO NPs group: treatment with BC films with immobilized ZnO NPs (5\%) (Figure S7).

2. BC-BDP group: treatment with BC films with immobilized BDP (0.01\%) (Figure S8).

3. BC-ZnO NPs-BDP group: treatment with BC films with immobilized ZnO NPs (5\%) and containing betulin diphosphate (1.5\%) (Figure S9).

4. Control group: treatment with ZnO NPs-BDP oleogels (Figure S10).

Healing was studied using film composites based on bacterial cellulose (BC) with zinc oxide nanoparticles ( $\mathrm{ZnO} N \mathrm{NP}$ ), BC and betulin diphosphate (BDP), and BC with ZnO NPs and BDP in the form of a film and gel, using 12 rats in each group. Postmortem studies were performed on days $3,7,10$, and 21 using 3 rats each time.

Post-mortem examination after 3, 7, 10 and 21 days of treatment in all cases of using film composite materials revealed that the liver, kidneys, spleen, lungs, and heart are normal. The adrenal glands are slightly enlarged. On the 7th day, when the external dressings were changed, cellulose "ingrowth" into the wound was noted. The edges of the film outside the wound did not adhere to the skin surface.

The difference between the treatment with the BC-BDP composite film coating (Figure S8) is the uneven adhesion and, accordingly, the film's ingrowth into the rat skin wound. In the presence of $\mathrm{ZnO} N \mathrm{Ns}$, the film grows into the skin more uniformly.

The best skin state was shown in the experimental group treated by films BC-ZnO NPs containing $1 \%$ BDP. There was a tight adhesion of the film and ingrowth into the wound throughout the entire wound area (Figure S9).

Figure S10 shows photographs of rat wounds treated with oleogel.

Wound healing was monitored by wound area measurement. On the 3rd day of healing, the area of wounds increased insignificantly (by $2-5 \%$ ), which is probably due to the development of burn disease in the animal. On day 21, the wound area treated with BC-ZnO NPs-BDP films was reduced by $34.3 \%$, while when treated with ZnO NPs-BDP oleogel, a large decrease up to $40.6 \%$ was observed (Table 8 ).

Table 8. Wound area changes during treatment with BC, BC-ZnO NPs-BDP (film), and ZnO NPs-BDP oleogel ( $n=5$, $p<0.001)$.

\begin{tabular}{|c|c|c|c|c|c|}
\hline \multirow{2}{*}{ Group } & \multicolumn{5}{|c|}{ Wound Area, $\mathrm{cm}^{2}$} \\
\hline & 0 Day & 3 Day & 7 Day & 10 Day & 21 Day \\
\hline Burn untreated & $21.643 \pm 0.920$ & $21.409 \pm 0.835$ & $20.772 \pm 0.659$ & $20.438 \pm 0.899$ & $17.492 \pm 1.015$ \\
\hline $\mathrm{BC}$ & $21.319 \pm 0.932$ & $21.282 \pm 1.085$ & $20.639 \pm 0.599$ & $19.921 \pm 1.331$ & $17.695 \pm 2.532$ \\
\hline BC-ZnO NPs-BDP (film) & $21.846 \pm 0.679$ & $21.645 \pm 1.294$ & $19.953 \pm 0.291$ & $19.455 \pm 0.544$ & $14.343 \pm 0.756$ \\
\hline Oleogel ZnO NPs-BDP & $21.599 \pm 0.628$ & $20.366 \pm 0.306$ & $18.798 \pm 0.307$ & $19.897 \pm 0.313$ & $12.825 \pm 0.311$ \\
\hline
\end{tabular}

Comparing the state of the burn wound on day 21 after treatment with the studied drugs showed that despite a smaller reduction in the wound area, the state of the burn wound when treated with BC-ZnO NPs-BDP films was the best (Figure 11). The healing process in rats is associated with skin tightening (construction), which is inhibited in the case of treatment with $\mathrm{BC}$ films, which partially grows into the wound. The skin in the wound area after treatment with oleogels looks inflamed, and small areas with suppuration were observed during treatment with BC-BDP films. Treatment with BC-ZnO NPs films in the absence of BDP reduced the wound area more slowly. 


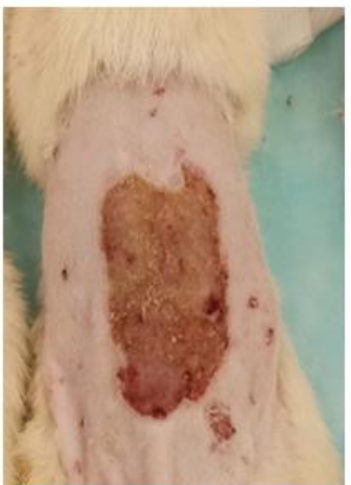

BC-ZnO NPs-BDP

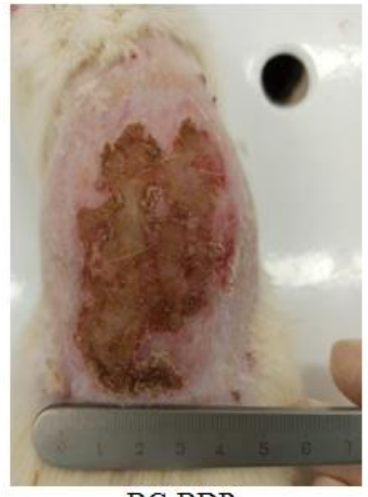

BC-BDP

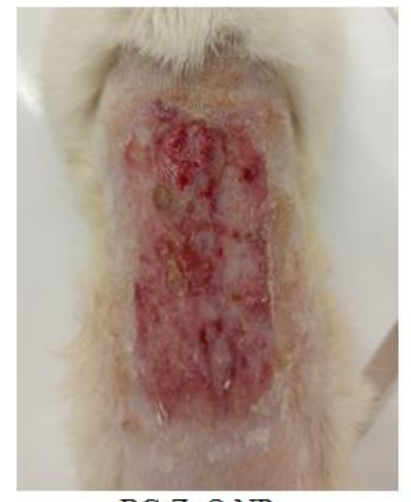

$\mathrm{BC}-\mathrm{ZnO} \mathrm{NPs}$

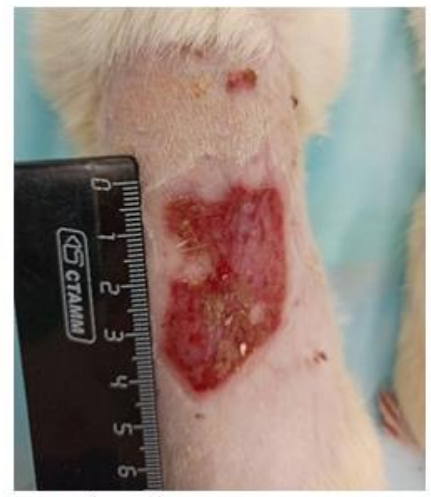

Oleogel $\mathrm{ZnO}$ NPs-BDP

Figure 11. The burn wound state on day 21 after treatment.

Morpho-histological studies have shown that on the third day after burn, all groups have a comparable histological picture. The histological structure of the epidermal tissue is disturbed. Destructive and degenerative processes in the upper layers of the dermis of animals were revealed. Infiltrative processes are accompanied by numerous foci of coagulation and total and subtotal necrosis. The end part, as well as the excretory duct of the sweat glands, are disturbed. The hair follicle is emptied and its own hair is missing. Coagulation necrosis encompasses both papillary and reticular dermis (Figure S11).

On the 7th day, common destructive changes in the epidermis and dermis persist in all groups. The epidermis is absent on almost the entire wound surface, except for the peripheral sections.

7 days after fixation of the $\mathrm{BC}-\mathrm{ZnO} \mathrm{NPs}, \mathrm{BC}-\mathrm{BDP}$, and $\mathrm{BC}-\mathrm{ZnO}$ NPs-BDP films, the scabs over the entire affected skin surface were almost completely desquamated. In the dermal plate's deep layers and the hypodermis, the edema disappeared, and the blood vessels narrowed somewhat. The granulation tissue layer consisted of numerous newly formed thin collagen fibers. A large number of thin-walled small vessels of the capillary type and fibroblastic cells were revealed. A similar, however weaker, effect was observed in the group using the ZnO NPs-BDP-B oleogel (Figure S12).

On the 10th day of the experiment, animals of the ZnO NPs-BDP-B oleogel group in the affected zone revealed a wide band of granulation tissue with thin multidirectional collagen fibers. Granulation tissue with macrophages, lymphocytes, fibroblastic cells of varying degrees of maturity, and well-differentiated and poorly differentiated cells was observed. On the 10th day of the experiment, in animals of the BC-ZnO NPs-BDP group, the bottom of the burn wound was filled with granulations, signs of the transition of granulation tissue into connective tissue appeared, and vascular invasion was noted.

The skin's epithelial layer was not restored in the BC-ZnO NPs and BC-BDP groups, even on the 10th day of the thermal burn zone experiment. A small zone of growing epithelium was determined from the periphery only. The exudate accumulation was revealed with its spread to the adjacent granulation tissue, which was represented by thin connective tissue fibers (Figure S13).

By the 21st day of the experiment, in animals of the BC-ZnO NPs, BC-BDP groups, the formed dermal plate was mostly represented by mature fibrous connective tissue, consisting of collagen bundle fibers infiltrated by fibroblastic cells. An even layer of the stratified keratinizing epithelium covering it lay on a clearly expressed thin basement membrane.

By the 21st day of the experiment, the BC-ZnO NPs-BDP group showed signs of parallel processes of maturation of granulation tissue and epithelialization of the regeneration. In the ZnO NPs-BDP-B oleogel group, partial peripheral epithelialization can be traced (Figure S14).

Based on the morphophysiological studies of tissue during treatment with various drugs based on composite materials (BC-ZnO NPs, BC-BDP, BC-ZnO NPs-BDP) and 
oleogel (ZnO NPs-BDP-B), additionally protected by dressings, we can draw the following conclusions:

1. At the initial stage, the healing of a thermal burn with the use of composite materials based on BC: BC-ZnO NPs, BC-BDP, BC-ZnO NPs-BDP, and ZnO NPs-BDP-B oleogel is similar. This process is characterized by destructive changes in the skin with signs of complications of the reparative process, which is manifested by uneven maturation of granulation tissue with the presence of foci of inflammation and secondary stromal necrosis and signs of impaired proliferation, differentiation, and keratinization of the epidermis in the form of focal hyperplasia of the epidermis with symptoms of acanthosis and hyperkeratosis.

2. The use of $\mathrm{ZnO}$ NPs-BDP-B oleogel, as a rule, limits the destructive changes caused by thermal damage within the epidermis and dermis. The use of ZnO NPs-BDP-B oleogel promotes granulation tissue formation, its maturation, and epithelialization. Simultaneously, the reparative process during treatment with oleogel proceeds to a lesser extent than the BC-ZnO NPs, BC-BDP and BC-ZnO NPs-BDP animal groups, complicated by the secondary stromal necrosis and inflammation foci of the regenerate and adjacent tissues.

3. Reparative processes when using $\mathrm{BC}$ composite materials proceed more intensively than using oleogel due to the destructive process's limitation within the epidermis and dermis. Besides, the purulent-necrotic complications are absent in the process of defect healing by $\mathrm{BC}$ composites. In this case, the reparative process ensures the earlier appearance and uniform maturation of young connective tissue with the normalization of proliferation and differentiation of epidermal cells.

3.5. Investigation of Microhemocirculation in the Skin of Rats after a Burn and during Treatment with Agents Containing Bacterial Cellulose

Microcirculation intensity also assessed the burn wound's state by using laser Doppler flowmetry (LDF), where laser radiation is reflected from the tissue. This method is based on the Doppler frequency shift depending on erythrocytes' speed in arterioles, capillaries, and venules [24].

There are various types of oscillations with different amplitudes, characterizing changes in microhemocirculation, to which the endothelial (E), myogenic (M), and neurogenic $(\mathrm{N})$ frequency ranges, which determine the mechanisms of regulation of the lumen of blood vessels and their tone, contribute.

The information obtained by the LDF method makes it possible to measure the rate of movement of erythrocytes and the amount of tissue oxygenation in the blood flow (perfusion). Small fluctuations in oxygenation of a burn wound's tissue generally reflected that metabolic changes can also be evaluated.

The average amplitude of the reflected signal in the microhemocirculatory flow makes it possible to obtain the average Doppler frequency shift over all the probed areas. We analyzed the amplitude-frequency spectrum using the wavelet transform [60].

The result of flowmetry can be represented by an indicator of microcirculation (PM), proportional to the number and average speed of erythrocytes in the probed volume and is expressed in arbitrary units (perfusion units).

Figure S15 shows typical LDF-grams and their wavelet spectra obtained immediately after the burning (day 0 ) and on day 10 after burning. Immediately after the burn, microcirculation and respiration (oxygenation) are disturbed in all areas of the microhemocirculatory zone (Figure S15a). On the 10th day after the burn, oxygenation of the microvasculature tissue (respiratory and cardiac bands of wavelet spectra) normalizes and reaches the maximum value. At the same time, all other LDF signals decrease (Figure S15b).

The dynamics of perfusion change as different microhemocirculatory indexes calculated by neurogenic, myogenic, cardiac, endothelial, and respiratory bands in wavelet spectra are shown in Tables 9 and 10. 
Table 9. Results of Doppler flowmetry of blood microcirculation in a burn wound under the action of bacterial cellulose wound dressings $(p<0.001)$.

\begin{tabular}{cccccccc}
\hline Time, Day & Group & MI, perf. un. ${ }^{\mathbf{1}}$ & E, arb. un. $^{\mathbf{2}}$ & $\mathbf{N}$, arb. un. & M, arb. un. & R, arb. un. & C, arb. un. \\
\hline N/A & healthy & $13.26 \pm 1.21$ & $6.63 \pm 0.60$ & $6.14 \pm 0.56$ & $7.64 \pm 0.69$ & $22.72 \pm 2.07$ & $11.80 \pm 1.07$ \\
0 & & $6.31 \pm 0.57$ & $12.63 \pm 1.15$ & $14.68 \pm 1.33$ & $15.66 \pm 1.42$ & $14.14 \pm 1.29$ & $9.66 \pm 0.88$ \\
3 & & $12.96 \pm 1.18$ & $5.25 \pm 0.48$ & $6.73 \pm 0.61$ & $6.92 \pm 0.63$ & $24.95 \pm 2.27$ & $12.05 \pm 1.10$ \\
7 & \multirow{2}{*}{ burnt } & $15.16 \pm 1.38$ & $6.05 \pm 0.55$ & $6.76 \pm 0.61$ & $8.61 \pm 0.78$ & $18.99 \pm 1.73$ & $11.53 \pm 1.05$ \\
10 & & $14.86 \pm 1.35$ & $6.67 \pm 0.61$ & $6.43 \pm 0.58$ & $7.94 \pm 0.72$ & $21.07 \pm 1.92$ & $10.72 \pm 0.97$ \\
21 & & $12.17 \pm 1.11$ & $7.34 \pm 0.67$ & $7.21 \pm 0.66$ & $6.13 \pm 0.56$ & $20.13 \pm 1.83$ & $9.43 \pm 0.86$ \\
\hline
\end{tabular}

${ }^{1}$ perf. un.: perfusion units, ${ }^{2}$ arb. un.: arbitrage units, E: endothelial, N: neurogenic, M: myogenic, R: respiratory and C: cardiac oscillations.

Table 10. Results of Doppler flowmetry of blood microcirculation in a burn wound under the action of control oleogel ( $p<0.001)$.

\begin{tabular}{cccccccc}
\hline Time, Day & Group & MI, perf. un. ${ }^{\mathbf{1}}$ & E, arb. un. ${ }^{\mathbf{2}}$ & N, arb. un. & M, arb. un. & R, arb. un. & C, arb. un. \\
\hline N/A & healthy & $13.26 \pm 1.21$ & $6.63 \pm 0.60$ & $6.14 \pm 0.56$ & $7.64 \pm 0.69$ & $22.72 \pm 2.07$ & $11.80 \pm 1.07$ \\
0 & & $6.31 \pm 0.57$ & $12.63 \pm 1.15$ & $14.68 \pm 1.33$ & $15.66 \pm 1.42$ & $14.14 \pm 1.29$ & $9.66 \pm 0.88$ \\
3 & & $11.47 \pm 1.04$ & $5.69 \pm 0.52$ & $6.51 \pm 0.59$ & $7.28 \pm 0.66$ & $27.87 \pm 2.53$ & $12.53 \pm 1.14$ \\
7 & \multirow{2}{*}{ burnt } & $13.05 \pm 1.19$ & $6.00 \pm 0.55$ & $6.82 \pm 0.62$ & $7.81 \pm 0.71$ & $23.71 \pm 2.16$ & $10.42 \pm 0.95$ \\
10 & & $13.19 \pm 1.20$ & $5.66 \pm 0.51$ & $7.17 \pm 0.65$ & $7.56 \pm 0.69$ & $23.08 \pm 2.10$ & $9.40 \pm 0.85$ \\
21 & & $13.20 \pm 1.20$ & $5.76 \pm 0.52$ & $7.78 \pm 0.71$ & $6.85 \pm 0.62$ & $21.23 \pm 1.93$ & $10.47 \pm 0.95$ \\
\hline
\end{tabular}

${ }^{1}$ perf. un.: perfusion units, ${ }^{2}$ arb. un.: arbitrage units, E: endothelial, N: neurogenic, M: myogenic, R: respiratory and C: cardiac oscillations.

Thus, the spectroscopic data of the LDF method after wavelet transformation characterize the recovery of the velocity of erythrocytes and the value of tissue oxygen saturation in the blood flow (perfusion) after treatment with the proposed BC-ZnO NPs-BDP wound dressings.

\subsection{Antioxidant Properties of BC-ZnO NPs-BDP Nanocomposites}

Main oxidative stress markers are the level of malondialdehyde (MDA) in blood plasma and erythrocytes and the level of activity of antioxidant defense enzymes such as superoxide dismutase and catalase (Figures 12 and 13, Table 11).

From the study results, it follows that the treatment of a burn wound with the studied drugs normalizes the MDA level by 7, 10, and 21 days.

The data in Figure 13 (SOD) and Table 11 (catalase) follows that the studied drugs, in particular wound dressings, exhibit antioxidant properties. On the 21st day, the SOD activity increases by $27 \%$ compared to the intact control, and the catalase activity practically reaches the intact control.

The significant effect of zinc oxide nanoparticles on the activity of SOD can be partially explained by the activation of the zinc in the active site of CuZn-SOD, which has extremely high stability and high activity of superoxide dismutation.

The zinc role, which does not change the oxidation state in redox protection against oxidative stress, is more complex than copper, which interacts according to the Fenton reaction. In this context, zinc can be considered an "indirect" antioxidant-a modifier of biological redox reactions. The antioxidant effect of zinc is mainly due to its ability to induce a stress response in terms of (1) stimulation of MTF-1-dependent transcription and (2) activation of stress-sensitive signalling cascades MAPK and PI3K/Akt. Besides, zinc's antioxidant effect is associated with the stabilization of protein thiols (enzymes, zinc fingers, metallothioneins) [16]. 

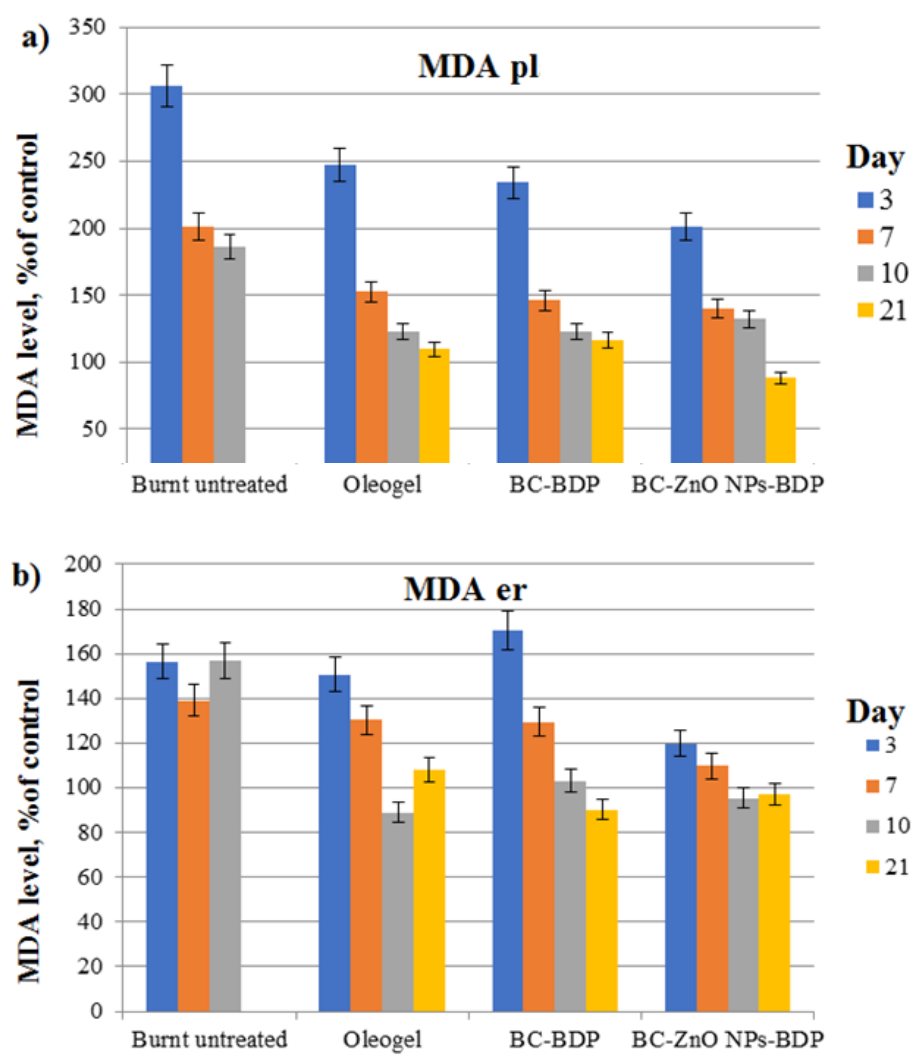

Figure 12. Diagram of changes in MDA concentration in plasma and blood erythrocytes $(\mu \mathrm{mol} / \mathrm{L})$ during treatment with the studied drugs (\% of control). Number of experiment replications was equal to 3. $p<0.001$. MDA pl (a) and MDA er (b) mean the level of MDA in blood plasma and erythrocytes.

\section{SOD activity}

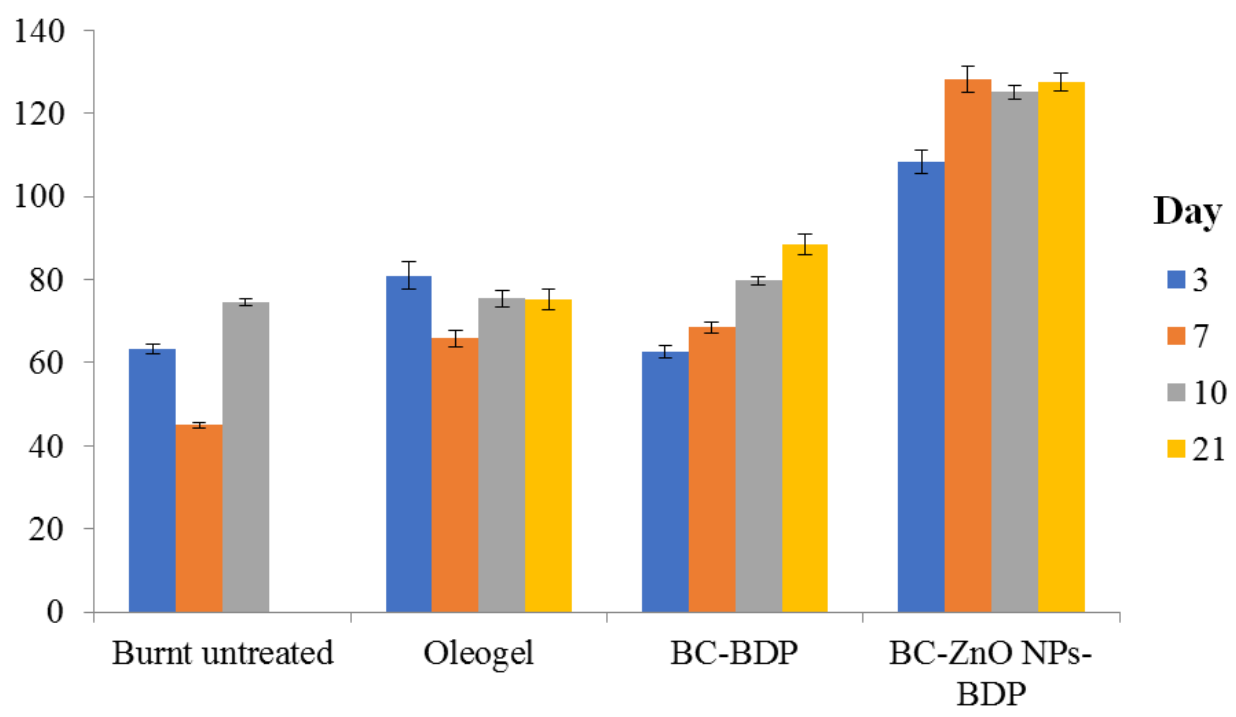

Figure 13. Diagram of changes in superoxide dismutase (SOD) activity during treatment with the studied agents (\% of control), $100 \%-1037.762 \pm 21.351 \% \mathrm{ng} \mathrm{min}^{-1} \mathrm{mg}$ protein ${ }^{-1}$. The number of experiment replications was equal to 3. $p<0.001$. 
Table 11. Catalase activity under the treatment with the studied agents (\% of control $)^{1,2}$.

\begin{tabular}{ccccc}
\hline \multirow{2}{*}{$\tau$, Day } & \multicolumn{4}{c}{ Catalase Activity, \% of Control } \\
\cline { 2 - 5 } & Burnt Untreated & Oleogel & BC-BDP & BC-ZnO NPs-BDP \\
\hline 3 & $47.98 \pm 1.16$ & $50.03 \pm 1.85$ & $57.50 \pm 0.82$ & $53.11 \pm 1.81$ \\
7 & $60.13 \pm 1.78$ & $50.71 \pm 1.09$ & $50.77 \pm 0.66$ & $86.71 \pm 3.84$ \\
10 & $51.89 \pm 2.54$ & $59.38 \pm 2.08$ & $58.90 \pm 1.11$ & $60.41 \pm 0.98$ \\
21 & N/A & $62.39 \pm 1.62$ & $65.84 \pm 0.42$ & $92.49 \pm 3.02$ \\
\hline
\end{tabular}

${ }^{1} 100 \%-39.512 \pm 0.903 \mu \mathrm{mol} \mathrm{H} \mathrm{O}_{2} \mathrm{~min}^{-1} \mathrm{mg}$ protein ${ }^{-1},{ }^{2}$ The number of experiment replications was equal to 3 . $p<0.001$

Potential mechanisms of action of zinc can be explained by antagonism of redox transition metals, such as iron or copper, and prevention of oxidation of sulfhydryl groups in proteins. Thiol groups are stabilized by zinc, which protects the enzyme or other protein from inactivation caused by oxidative stress. The action of zinc as an antioxidant in the case of metallothioneins is to regulate their metabolism. In turn, zinc deficiency leads to a decrease in the protection of sulfhydryl groups and an increase in reactive oxygen species (ROS). Excessive levels of zinc can act as prooxidants, causing a decrease in the level of $\mathrm{CuZn-SOD}$ and other important metalloenzymes in erythrocytes. In general, biochemical studies of many diseases, such as diabetes mellitus, have confirmed that optimal zinc levels are a prerequisite for maintaining normal oxidative metabolism [16].

Thus, our studies have shown that by day 21, wound dressings based on $\mathrm{BC}$ and $\mathrm{ZnO}$ NPs with immobilized BDP lead to the restoration of the antioxidant balance in the blood of rats with thermal injury both by reducing the intensity of free radical oxidation and by increasing the antioxidant enzyme protection.

\section{Conclusions}

A nanosized $B C$ hydrogel film has shown itself as a promising matrix for the sorption of anti-burn BDP and ZnO NPs modified with BDP. Zinc oxide nanoparticles protected by $\mathrm{BDP}$ do not aggregate in both the individual state and in the nanocomposite. Moreover, zinc ions release and cell survival results are the arguments for the decrease in the protein corona formation on $\mathrm{ZnO}$ NPs surfaces. The results of biological studies carried out by us on rats (wound area, improved healing, biochemical parameters and microcirculation, morphological picture) indirectly confirm the perspective of medical use of ZnO NPs modified with betulin diphosphate as a component of nanocomposites. In general, it creates the prerequisites for high stability and uniformity of the final BC-Zn NPs-BDP nanomaterial. Our cell viability data show that the BC-Zn NPs-BDP nanocomposite toxicity is reduced due to the protection of zinc oxide nanoparticles by the BDP modification. It was found that BC-Zn NPs-BDP demonstrated a set of properties necessary for wound dressings to treat burns in in vivo experiments. These coatings can accelerate wound healing due to the inclusion of several mechanisms: regulation of oxygenation and microcirculation, reduction of hypoxia in a burn wound, reduction of oxidative stress resulting from the development of burn disease, and activation of antioxidant enzymatic protection.

Supplementary Materials: The following are available online at https://www.mdpi.com/2079-499 1/11/3/713/s1, Figure S1: ${ }^{13} \mathrm{C}$ NMR spectrum of solid bacterial cellulose, Figure S2: Fluorescence spectra of $27.2 \mathrm{mg} \%$ dispersions of ZnO NPs (a); UV spectrum of ZnO NPs in ethanol, $27.2 \mathrm{mg} / \%$, blanc-ethanol (b), Figure S3: MS spectrum of BDP, Figure S4: FTIR spectra characteristics of ZnO $\mathrm{NPs}$, bacterial cellulose (aerosol) samples and aerosol bacterial cellulose with immobilized betulin diphosphate under various conditions, Figure S5: FTIR spectra characteristics of BDP, BC + BDP (1\%) and $\mathrm{BC}+\mathrm{BDP}(1 \%)+\mathrm{ZnO}(5 \%)$, Figure S6: Scheme of the Franz vertical diffusion cell, Figure S7: Treatment by BC-ZnO NPs composite, Figure S8: Treatment by BC-BDP composite, Figure S9: Treatment by BC-ZnO NPs-DBP composite, Figure S10: Treatment by ZnO NPs-BDP-B oleogel, Figure S11: Tissue state by morphological and histological examination (3 Day, hematoxylin-eosin, $\times 600$ ), Figure S12: Tissue state by morphological and histological examination (7 Day, hematoxylin- 
eosin, $\times 600$ ), Figure S13: Tissue state by morphological and histological examination (10 Day, hematoxylin-eosin, $\times 600$ ), Figure S14: Tissue state by morphological and histological examination (21 Day, hematoxylin-eosin, $\times 600$ ), Figure S15: Typical LDF grams and the corresponding wavelet spectra obtained immediately after the burning ( 0 day) and on day 10 after burning on the wounds of rats. E: endothelial, N: neurogenic; M: myogenic, R: respiratory, and C: cardiac oscillations.

Author Contributions: N.M. conceived and designed the experiments, analyzed the data, and wrote the paper; V.N. performed morpho-histological experiments; K.B. performed biochemical experiments, A.K. performed PXRD analysis; P.P. evaluated microhemocirculation indexes; E.L., and N.N. obtained BC; D.M. obtained nanocomposites; V.R. discussed the results. All authors have read and agreed to the published version of the manuscript.

Funding: This research was funded by the Russian Foundation for Basic Research (grant number 19-515-80002/19). The results of Section 3.3 were obtained within the state assignment of the Ministry of Science and Higher Education of the Russian Federation (grant number FZRS-2020-0003).

Institutional Review Board Statement: All procedures for maintenance and sacrifice (care and use) of animals were carried out according to the criteria outlined by European Convention ET/S 129, 1986 and directives 86/609 ESC. The study as presented was approved by the Local Ethics Committee of Privolzhsky Research Medical University, Russian Federation (Protocol No. 2 from 20 February 2016 and Protocol No. 1 from 18 January).

Informed Consent Statement: No patient studies have been performed.

Data Availability Statement: Not applicable.

Acknowledgments: The SEM: ICP and SSAs studies were carried out on the equipment of the Collective Usage Center “New Materials and Resource-saving Technologies" (Lobachevsky State University of Nizhniy Novgorod).

Conflicts of Interest: The authors declare no conflict of interest.

\section{References}

1. Beekmann, U.; Zahel, P.; Karl, B.; Schmölz, L.; Börner, F.; Gerstmeier, J.; Werz, O.; Lorkowski, S.; Wiegand, C.; Fischer, D.; et al. Modified Bacterial Cellulose Dressings to Treat Inflammatory Wounds. Nanomaterials 2020, 10, 2508. [CrossRef]

2. Drag-Zalesińska, M.; Rembiałkowska, N.; Borska, S.; Saczko, J.; Drąg, M.; Poręba, M.; Kulbacka, J. A New Betulin Derivative Stimulates the Synthesis of Collagen in Human Fibroblasts Stronger than its Precursor. In Vivo 2019, 33, 1087-1093. [CrossRef] [PubMed]

3. Melnikova, N.; Vorobyova, O.; Balakireva, A.; Malygina, D.; Solovyeva, A.; Belyaeva, K.; Orekhov, D.; Knyazev, A. The New Pharmaceutical Compositions of Zinc Oxide Nanoparticles and Triterpenoids for the Burn Treatment. Pharmaceuticals 2020, 13, 207. [CrossRef]

4. Vorobyova, O.; Deryabina, O.; Malygina, D.; Plotnikova, N.; Solovyeva, A.; Belyaeva, K.; Melnikova, N. Betulin-3,28-diphosphate as a Component of Combination Cytostatic Drugs for the Treatment of Ehrlich Ascites Carcinoma In Vitro and In Vivo Experiments. Sci. Pharm. 2018, 86, 17. [CrossRef] [PubMed]

5. Khalid, A.; Khan, R.; Ul-Islam, M.; Khan, T.; Wahid, F. Bacterial cellulose-zinc oxide nanocomposites as a novel dressing system for burn wounds. Carbohydr. Polym. 2017, 164, 214-221. [CrossRef]

6. Luo, Z.; Liu, J.; Lin, H.; Ren, X.; Tian, H.; Liang, Y.; Wang, W.; Wang, Y.; Yin, M.; Huang, Y.; et al. In situ Fabrication of Nano $\mathrm{ZnO} / \mathrm{BCM}$ Biocomposite Based on MA Modified Bacterial Cellulose Membrane for Antibacterial and Wound Healing. Int. J. Nanomed. 2020, 15, 1-15. [CrossRef] [PubMed]

7. Dincă, V.; Mocanu, A.; Isopencu, G.; Busuioc, C.; Brajnicov, S.; Vlad, A.; Icriverzi, M.; Roseanu, A.; Dinescu, M.; Stroescu, M.; et al. Biocompatible pure $\mathrm{ZnO}$ nanoparticles-3D bacterial cellulose biointerfaces with antibacterial properties. Arab. J. Chem. 2020, 13, 3521-3533. [CrossRef]

8. Pirsa, S.; Shamusi, T.; Kia, E.M. Smart films based on bacterial cellulose nanofibers modified by conductive polypyrrole and zinc oxide nanoparticles. J. Appl. Polym. Sci. 2018, 135, 46617. [CrossRef]

9. Zheng, W.; Hu, W.; Chen, S.; Zheng, Y.; Zhou, B.; Wang, H. High photocatalytic properties of zinc oxide nanoparticles with amidoximated bacterial cellulose nanofibers as templates. J. Polym. Sci. Polym. Symp. 2014, 32, 169-176. [CrossRef]

10. Mocanu, A.; Isopencu, G.; Busuioc, C.; Popa, O.-M.; Dietrich, P.; Socaciu-Siebert, L. Bacterial cellulose films with ZnO nanoparticles and propolis extracts: Synergistic antimicrobial effect. Sci. Rep. 2019, 9, 17687. [CrossRef]

11. Katepetch, C.; Rujiravanit, R.; Tamura, H. Formation of nanocrystalline ZnO particles into bacterial cellulose pellicle by ultrasonicassisted in situ synthesis. Cellulose 2013, 201, 1275-1292. [CrossRef]

12. Zhao, S.-W.; Guo, C.-R.; Hu, Y.-Z.; Guo, Y.-R.; Pan, Q.-J. The preparation and antibacterial activity of cellulose/ZnO composite: A review. Open Chem. 2018, 16, 9-20. [CrossRef] 
13. Wasim, M.; Khan, M.R.; Mushtaq, M.; Naeem, A.; Han, M.; Wei, Q. Surface Modification of Bacterial Cellulose by Copper and Zinc Oxide Sputter Coating for UV-Resistance/Antistatic/Antibacterial Characteristics. Coatings 2020, 10, 364. [CrossRef]

14. Aritonang, H.F.; Kamea, O.E.; Koleangan, H.; Wuntu, A.D. Biotemplated synthesis of Ag-ZnO nanoparticles/bacterial cellulose nanocomposites for photocatalysis application. Polym.-Plast. Technol. Mater. 2020, 1-8. [CrossRef]

15. Ul-Islam, M.; Khattak, W.A.; Ullah, M.W.; Khan, S.; Park, J.K. Synthesis of regenerated bacterial cellulose-zinc oxide nanocomposite films for biomedical applications. Cellulose 2013, 21, 433-447. [CrossRef]

16. Wessels, I.; Maywald, M.; Rink, L. Zinc as a Gatekeeper of Immune Function. Nutrients 2017, 9, 1286. [CrossRef]

17. Holmes, A.M.; Song, Z.; Moghimi, H.R.; Roberts, M.S. Relative Penetration of Zinc Oxide and Zinc Ions into Human Skin after Application of Different Zinc Oxide Formulations. ACS Nano 2016, 10, 1810-1819. [CrossRef] [PubMed]

18. Martínez-Carmona, M.; Gun'ko, Y.; Vallet-Regí, M. ZnO Nanostructures for Drug Delivery and Theranostic Applications. Nanomaterials 2018, 8, 268. [CrossRef] [PubMed]

19. Ying, W. NAD+/NADH and NADP+/NADPH in cellular functions and cell death: Regulation and biological consequences. Antioxid. Redox. Signal. 2008, 10, 179-206. [CrossRef]

20. Liu, Z.-J. Observation and identification of lactate dehydrogenase anomaly in a postburn patient. Postgrad. Med. J. 2004, 80, 481-483. [CrossRef] [PubMed]

21. Ahmad, R.; Nazam, N.; Khan, A.; Alam, M. Significance of Serum Lactate Dehydrogenase and its Isoenzymes during Post-Burn Follow-Up. J. Med. Biochem. 2009, 28, 176-183. [CrossRef]

22. Luo, X.; Li, R.; Yan, L.-J. Roles of Pyruvate, NADH, and Mitochondrial Complex I in Redox Balance and Imbalance in $\beta$ Cell Function and Dysfunction. J. Diabetes Res. 2015, 2015, 1-12. [CrossRef] [PubMed]

23. Wang, H.J.; Chen, T.M.; Yang, T.S.; Wang, D.S.; Lin, S.Z. Regional skin blood flow in deep burn wounds: A preliminary report. Burns 1995, 21, 340-343. [CrossRef]

24. Krupatkin, A.I.; Sidorov, V.V. Functional Diagnostics of the State of Microcirculatory-Tissue Systems: Oscillations, Information, Nonlinearity: A Guide for Physicians; LIBROKOM Book House: Moscow, Russia, 2013; 496p.

25. Gupta, M.; Mahajan, V.K.; Mehta, K.S.; Chauhan, P.S. Zinc Therapy in Dermatology: A Review. Dermatol. Res. Pract. 2014, 2014, 1-11. [CrossRef]

26. Jiang, J.; Pi, J.; Cai, J. The Advancing of Zinc Oxide Nanoparticles for Biomedical Applications. Bioinorg. Chem. Appl. 2018, 2018, 1-18. [CrossRef]

27. Bhunia, A.K.; Samanta, P.K.; Saha, S.; Kamilya, T. ZnO nanoparticle-protein interaction: Corona formation with associated unfolding. Appl. Phys. Lett. 2013, 103, 143701. [CrossRef]

28. Yin, H.; Chen, R.; Casey, P.S.; Ke, P.C.; Davis, T.P.; Chen, C. Reducing the cytotoxicity of ZnO nanoparticles by a pre-formed protein corona in a supplemented cell culture medium. RSC Adv. 2015, 5, 73963-73973. [CrossRef]

29. Giau, V.-V.; Park, Y.-H.; Shim, K.-H.; Son, S.-W.; An, S.-S.A. Dynamic changes of protein corona compositions on the surface of zinc oxide nanoparticle in cell culture media. Front. Chem. Sci. Eng. 2019, 13, 90-97. [CrossRef]

30. Srivastav, A.K.; Dhiman, N.; Khan, H.; Srivastav, A.K.; Yadav, S.K.; Prakash, J.; Arjaria, N.; Singh, D.; Yadav, S.; Patnaik, S.; et al. Impact of surface engineered $\mathrm{ZnO}$ nanoparticles on protein corona configuration and their interactions with biological system. J. Pharm. Sci. 2019, 108, 1872-1889. [CrossRef] [PubMed]

31. Hassanian, M.; Aryapour, H.; Goudarzi, A.; Javan, M.B. Are zinc oxide nanoparticles safe? A structural study on human serum albumin using in vitro and in silico methods. J. Biomol. Struct. Dyn. 2021, 39, 330-335. [CrossRef]

32. Rao, A.; Long, H.; Harley-Trochimczyk, A.; Pham, T.; Zettl, A.; Carraro, C.; Maboudian, R. In situ localized growth of ordered metal oxide hollow sphere array on microheater platform for sensitive, ultra-fast gas sensing. ACS Appl. Mater. Interfaces 2017, 9, 2634-2641. [CrossRef]

33. Schöttler, S.; Landfester, K.; Mailänder, V. Controlling the stealth effect of nanocarriers through understanding the protein corona. Angew. Chem. Int. Ed. Engl. 2016, 55, 8806-8815. [CrossRef]

34. Melnikova, N.B.; Malygina, D.S.; Vorobyova, O.A.; Solovyeva, A.G.; Belyaeva, K.L.; Orekhov, D.V.; Knyazev, A.V. Properties of Langmuir and immobilized layers of betulin diphosphate on aqueous solutions of zinc sulfate and on the surface of zinc oxide nanoparticles. Russ. Chem. Bull. Int. Ed. 2021, 70, 289-300. [CrossRef]

35. Revin, V.V.; Liyas'kina, E.V.; Sapunova, N.B.; Bogatyreva, A.O. Isolation and characterization of the strains producing bacterial cellulose. Microbiology 2020, 14, 86-95. [CrossRef]

36. Revin, V.V.; Pestov, N.A.; Shchankin, M.V.; Mishkin, V.M.; Platonov, V.I.; Uglanov, D.A. A study of the physical and mechanical properties of aerogels obtained from bacterial cellulose. Biomacromolecules 2019, 20, 1401-1411. [CrossRef] [PubMed]

37. Mori, T.; Chikayama, E.; Tsuboi, Y.; Ishida, N.; Shisa, N.; Noritake, Y.; Moriya, S.; Kikuchi, J. Exploring the conformational space of amorphous cellulose using NMR chemical shifts. Carbohydr. Polym. 2012, 90, 1197-1203. [CrossRef] [PubMed]

38. Atalla, R.H.; Vander Hart, D.L. The role of solid state 13C NMR spectroscopy in studies of the nature of native celluloses. Solid State Nucl. Magn. Reson. 1999, 15, 1-19. [CrossRef]

39. Ek, R.; Wormald, P.; Iversen, T.; Nyström, C. Crystallinity index of microcrystalline cellulose particles compressed into tablets. Int. J. Pharm. 1995, 125, 257-264. [CrossRef]

40. Melnikova, N.B.; Malygina, D.S.; Klabukova, I.N.; Belov, D.V.; Vasin, V.A.; Petrov, P.S.; Knyazev, A.V.; Markin, A.V. Betulin-3,28diphosphate. Physico-Chemical Properties and In Vitro Biological Activity Experiments. Molecules 2018, 23, 1175. [CrossRef] 
41. Bera, D.; Qian, L.; Sabui, S.; Santra, A.; Holloway, P.H. Photoluminescence of ZnO quantum dots produced by a sol-gel process. Opt. Mater. 2008, 30, 1233-1239. [CrossRef]

42. Yang, W.; Zhang, B.; Ding, N.; Ding, W.; Wang, L.; Yu, M.; Zhang, Q. Fast synthesize ZnO quantum dots via ultrasonic method. Ultrason. Sonochem. 2015, 30, 103-112. [CrossRef]

43. Pakhomova, A.E.; Pakhomova, E.E.; Pakhomova, J.V.; Yavorsky, E.M. Method Experimental Modeling of Thermal Combustion at Laboratory. Animals. Patent No. RU 2,582,458 C1, 24 December 2014.

44. Pakhomova, A.E.; Pakhomova, J.V.; Ovsyanko, E.V.; Zhurakovsky, I.P.; Karabintseva, N.O.; Pakhomova, E.E. Preclinical research of repalen ointment at treatment of thermal combustions in experiment. J. Sib. Med. Sci. 2015, 3, 98.

45. Kochetygov, N.I. Burn Disease; Medicine: Leningrad, Russia, 1973; p. 247.

46. Hosseinimehr, S.J.; Khorasani, G.; Azadbakht, M.; Zamani, P.; Ghasemi, M.; Ahmadi, A. Effect of aloe cream versus silver sulfadiazine for healing burn wounds in rats. Acta Dermatovenerol. Croat. 2010, 18, $2-7$.

47. Martusevich, A.K.; Larionova, K.D.; Peretyagin, S.P.; Peretyagin, P.V.; Davyduk, A.V. Experimental estimation of pharmacological compositions effect on microcirculation state at early postburn period. Fundam. Res. 2013, 3, 332-336.

48. Dahmus, J.D.; Bruning, R.S.; Kenney, W.L.; Alexander, L.M. Oral clopidogrel improves cutaneuos microvascular function through EDHF-dependent mechanisms in middle-aged humans. Am. J. Physiol. Regul. Integr. Comp. Physiol. 2013, 305, R452-R458. [CrossRef] [PubMed]

49. Levdansky, V.; Kondrasenko, A.; Levdansky, A.; Kuznetsov, B. Synthesis of Betulin Diacetate and Betulin Dipropionate. J. Sib. Fed. Univ. Chem. 2016, 9, 337-344. [CrossRef]

50. Sirota, T.V. A new approach to studying the autoxidation of adrenaline: Possibility of the determination of superoxide dismutase activity and the antioxidant properties of various preparations by polarography. Biomed. Khi. 2012, 58, 77-87. [CrossRef] [PubMed]

51. Packer, L. Catalase in Vitro. In Methods in Enzymology; Academic Press: Cambridge, MA, USA, 1984; Volume 105, pp. 121-126. ISBN 012182005X.

52. Dawson, J.M.; Heatlic, P.L. Lowry method of protein quantification evidence for photosensitivity. Anal. Biochem. 1984, 140, 391-393. [CrossRef]

53. Stroescu, M.; Stoica-Guzun, A.; Jinga, S.I.; Dobre, T.; Jipa, I.M.; Dobre, L.M. Influence of sodium dodecyl sulfate and cetyl trimethylammonium bromide upon calcium carbonate precipitation on bacterial cellulose. Korean J. Chem. Eng. 2012, 29, 1216-1223. [CrossRef]

54. Melnikova, N.; Malygina, D.; Panteleev, D.; Vorobyova, O.; Solovyeva, A.; Belyaeva, K.; Klabukova, I. The improvement of betulin-3, 28-diphosphate water-solubility by complexation with amines-meglumine and xymedon. Int. J. Pharm. Pharm. Sci. 2019, 11, 48-55. [CrossRef]

55. Rupasinghe, R.A. Dissolution and Aggregation of Zinc Oxide Nanoparticles at Circumneutral pH; A Study of Size Effects in the Presence and Absence of Citric Acid. Master's Thesis, University of Iowa, Iowa, IA, USA, 2011.

56. Kuptsov, A.H.; Zhizhin, G.N. Handbook of Fourier Transform. Raman and Infrared Spectra of Polymers; Elsevier: Amsterdam, The Netherlands, 1998; Volume 45, p. 536.

57. Revin, V.V.; Nazarova, N.B.; Tsareva, E.E.; Liyaskina, E.V.; Revin, V.D.; Pestov, N.A. Production of Bacterial Cellulose Aerogels With Improved Physico-Mechanical Properties and Antibacterial Effect. Front. Bioeng. Biotechnol. 2020, 8, 1392. [CrossRef] [PubMed]

58. Wang, B.; Lv, X.; Chen, S.; Li, Z.; Sun, X.; Feng, C.; Wang, H.; Xu, Y. In vitro biodegradability of bacterial cellulose by cellulase in simulated body fluid and compatibility in vivo. Cellulose 2016, 23, 3187-3198. [CrossRef]

59. Hou, Y.; Wang, X.; Yang, J.; Zhu, R.; Zhang, Z.; Li, Y. Development and biocompatibility evaluation of biodegradable bacterial cellulose as a novel peripheral nerve scaffold. J. Biomed. Mater. Res. A 2018, 106, 1288-1298. [CrossRef] [PubMed]

60. Stefanovska, A.; Bracic, M.; Desiree Kvernmo, H. Wavelet Analysis of Oscillations in the Peripheral Blood Circulation Measured by Laser Doppler Technique. IEEE Trans. Biomed. Eng. 1999, 46, 1230-1239. [CrossRef] [PubMed] 